\title{
The Effects of Capital Requirements on Good and Bad Risk-Taking*
}

\author{
N. Aaron Pancost ${ }^{\dagger}$ and Roberto Robatto ${ }^{\ddagger}$
}

This version: December 11, 2018

\begin{abstract}
We study optimal capital requirement regulation in a dynamic quantitative model in which deposits facilitate real economic activity and thus the value of deposits is microfounded. We identify a novel general equilibrium effect that drives a wedge between the private value of deposits (i.e., the value to price-taking agents, measured by the deposit premium) and the social value of deposits (i.e., the value that matters for regulation). The wedge reduces the social value of deposits, and as a result, the optimal capital requirement is substantially higher than in comparable models in the literature. Nonetheless, even when the marginal social value of deposits is very low, setting capital requirements too high is suboptimal.
\end{abstract}

Keywords: deposit insurance, capital requirements, idiosyncratic risk, safe assets JEL Classifications: E21, G21, G32

${ }^{*}$ We thank Juliane Begenau (discussant), Itay Goldstein (discussant), Gregor Matvos, Oliver Levine, and Diego Vega San Martin (discussant) for helpful conversations and suggestions, as well as seminar participants at the University of Wisconsin-Madison, the 2018 ASSA annual meeting, the 2018 MFA annual meeting, the University of Texas at Austin McCombs School of Business, the 2018 EEA-ESEM meeting, the 2018 FDIC Annual Bank Research Conference, the 2018 Southern Finance Association Annual Meeting, and UCLA. Any remaining errors are our own. Financial support from the Wisconsin Alumni Research Foundation (WARF) is gratefully acknowledged.

†University of Texas at Austin, McCombs School of Business. Email address: aaron.pancost@mccombs.utexas.edu

${ }^{\ddagger}$ University of Wisconsin-Madison, Wisconsin School of Business. Email address: robatto@wisc.edu 


\section{Introduction}

After the 2007-2008 financial crisis, the revision of the regulatory framework of financial intermediaries has become a central topic of discussion by regulators and academics. The Basel III accord has tightened bank regulation with the aim of reducing the likelihood and depth of financial crises. One of the key sets of rules at the center of this debate is capital requirements, namely, limits on the fraction of debt that banks can use to finance their investment. Appealing to the Modigliani and Miller (1958) theorem, Admati and Hellwig (2013) argue that capital requirements should be raised even further to eliminate banks' bad risk-taking, namely, the moral hazard induced by government guarantees and implicit too-big-to-fail subsidies. Some regulators have made a case for similar rules as well; see for example the Minneapolis Plan discussed by Kashkari (2016).

The typical argument against tighter capital requirements is that banks are "special" because their liabilities are valued for their safety and liquidity (DeAngelo and Stulz, 2015). This value is often modeled in a simple way by assuming that deposits provide a direct flow of utility - that is, deposits are an argument of agents' utility functions - without modeling explicitly what deposits are used for (Van den Heuvel 2008, Davydiuk 2017, Begenau 2018). Under this view, raising capital requirements reduces excessive risky lending by banks, but at the cost of reducing the supply of valuable bank deposits. Optimal capital regulation trades off these costs and benefits; importantly, the welfare cost of changing capital requirements is measured using the deposit premium, that is, the spread between deposit rates and rates on similarly low-risk, but less liquid, investments.

In this paper, we provide a microfoundation of the usefulness of deposits that challenges the interpretation of the deposit premium as a measure of the cost of raising capital requirements. Deposits in our model are held by firms for precautionary reasons and facilitate their acquisition of production inputs. If financial regulation is relaxed and the availability of deposits increases, firms will try to hire more inputs to increase their production. Yet, in general equilibrium, input prices will increase, partially offsetting firms' willingness to hire more inputs. Unlike the models in the literature that use deposits in the utility function, the deposit premium in our model measures only the firms' private value of deposits, whereas the social value of deposits that is relevant for regulators also includes general equilibrium forces.

Our main result is that the optimal capital requirement is higher than in comparable models used in the literature, in which the value of deposits is inferred using the deposit premium. In these models, in which deposits enter agents' utility functions, the regulator's social value of deposits is equal to the private value. Thus, a regulator that uses these 
models may over-value deposits by ignoring the general equilibrium effects of raising capital requirements that we identify. We compute the difference between the optimal capital requirement according to the social and private values of deposits and find it is substantial. In addition, the mistaken regulator that uses the private value of deposits perceives much larger welfare losses of setting capital requirements too high. Nevertheless, for reasonable parameterizations, the optimal capital requirement is not as high as the level advocated by Admati and Hellwig (2013).

Although our results show the possible shortcomings of deposits-in-the-utility-function models, several other aspects of our work build heavily on the very same papers that use this approach to quantify optimal capital requirements. We emphasize the importance of dynamic, quantitative, general equilibrium considerations to study capital requirements, pioneered by Van den Heuvel (2008), and some elements of both our theoretical and quantitative analyses are based on Van den Heuvel (2008), Davydiuk (2017), and Begenau (2018). ${ }^{1}$

Our model builds on a framework introduced by Quadrini (2017), in which deposits are held by firms subject to uninsurable idiosyncratic shocks to the productivity of their employees. The wage bill must be paid independently of the realization of the shocks, and thus the productivity risk is borne by the firm. The effect of these shocks is to reduce the firm's labor demand relative to an economy without idiosyncratic shocks. Because deposits are safe, they reduce the volatility of firms' cash flows, so that a high availability of and return on deposits increases firms' willingness to hire workers. We call this channel "good risk-taking" because increasing labor demand is in general socially valuable but not fully exploited due to the lack of insurance against idiosyncratic risk. The fact that non-financial firms in our model hold financial assets is consistent with the well-known large increase in firms' cash holdings over the last few decades (Bates, Kahle and Stulz, 2009).

Tighter capital requirements reduce firms' labor demand in the model; however, the ultimate impact on welfare depends on what happens to the equilibrium level of employment, which is affected not only by labor demand but also by labor supply. To clarify this point, our theoretical analysis shows the results of an extreme parameterization of the model which implies a fixed labor supply. In this case, the marginal social value of deposits is zero, even if the deposit premium is still positive. ${ }^{2}$ Crucially, a drop in labor demand reduces wages in

\footnotetext{
${ }^{1}$ In addition, we abstract from some features that have been studied in other papers, such as the interactions with the shadow banking system (Begenau and Landvoigt, 2017; Dempsey, 2017), the possible optimality of time-varying capital requirements (Davydiuk, 2017; Malherbe, 2017), the effect of legacy assets (Bahaj et al., 2016; Bahaj and Malherbe, 2018), and the interaction with economic growth (Nguyễn, 2014).

${ }^{2}$ Note that we are discussing the marginal value of deposits (either private or social), rather than their total value. This is because, even if the marginal social value of deposits can be as low as zero in our model, deposits might need to be at or above some minimum threshold to make sure that firms have enough safe assets to operate. Thus, the optimal capital requirement is not $100 \%$.
} 
general equilibrium, but does not produce any impact on welfare through the labor market because employment is fixed. This is not to say that capital requirements are irrelevant: even in this extreme case, tightening capital requirements alters bad risk-taking by banks.

Under a proper calibration of the key labor market parameters, changing capital requirements affects both wages and employment. Nonetheless, our main message is unaltered. When deciding on the amount of deposits to hold, each firm makes its decisions based on the marginal private benefit of deposits. However, marginal private benefits take the wages paid to employees as given. In contrast, the marginal social benefit of deposits accounts for the fact that wages may adjust in general equilibrium. If wages drop in response to tighter capital requirements, the wage bill of firms decreases, and a bad idiosyncratic shock does not preclude a firm from financing future projects even if it has fewer deposits.

The impact of our channel is quantitatively relevant. After presenting a baseline model to describe the results, we extend it to include several quantitative features. The optimal capital requirement in the quantitative model is $18.5 \%$, and thus substantially higher than in many models in the literature. More importantly, however, we argue that the wedge between private and social value of deposits is large in the context of our model, in which some features are different than in many related papers. To make this argument, we solve for the capital requirement that would be chosen by a regulator that mistakenly uses the private rather than the social value of deposits for welfare calculations. In our calibrated quantitative model, this mistaken regulator would choose a $10.2 \%$ capital requirement, substantially lower than the optimal $18.5 \%$.

We argue that government guarantees and capital requirements are important for firms' deposits. Indeed, even if some firms might have high deposit balances, the government has been covering deposits and other banks' liabilities well beyond the deposit insurance limit. For instance, Veronesi and Zingales (2010) calculate that the Paulson's equity-infusion plan implemented during the Columbus-day weekend of October 2008 - at the height of the crisis - entailed a transfer of $\$ 21-\$ 44$ billion from taxpayers to the holders of liabilities of some of the largest US banks. This is a large number, when compared to $\$ 90$ billion costs borne by the Deposit Insurance Fund between 2007 and 2013 (Davison and Carreon, 2010), and is likely a lower bound on the overall taxpayers-subsidized transfers because of the numerous interventions at that time.

Capital requirements are introduced in our model to limit the negative impact of subsidized deposits insurance. More generally, though, deposit insurance can also be interpreted as any explicit or implicit government guarantee on bank debt (e.g., the Temporary Liquidity Guarantee Program set up by the Federal Deposit Insurance Corporation in 2008 and the too-big-to-fail guarantee that resulted in the Paulson's plan studied by Veronesi and Zin- 
gales, 2010). We follow a common approach in the literature that imposes deposit insurance and motivates it with its role in preventing runs, as in Diamond and Dybvig (1983), but does not explicitly include runs nor analyze the optimality of such a policy. Nonetheless, we note that fully eliminating deposit insurance might not be optimal in our framework because it would make deposits unsafe, thereby increasing rather than reducing the volatility of firms' cash flows. We leave the joint determination of optimal deposit insurance and capital requirement regulation to future research.

We motivate firms' aversion to idiosyncratic risk with an agency problem, following a literature that has highlighted the importance of these frictions (Panousi and Papanikolaou, 2012; Glover and Levine, 2015, 2017). Firms are owned by households that can fully diversify away their exposure to idiosyncratic risk by holding a well-diversified portfolio of equity. However, each firm is run by a manager who holds only an equity stake in the firm she manages and thus is exposed to the idiosyncratic risk of the firm. As a separate contribution of the paper, we introduce some modeling assumptions that make the model tractable and allow us to ignore managers' consumption when performing welfare analysis, without altering the implications of the agency friction. In addition, even if idiosyncratic shocks create heterogeneity across firms, the equilibrium in our model depends only on aggregate firms' wealth, and other moments of the firm size distribution are irrelevant. As a result, we can easily aggregate firms' behavior, maintaining the main focus on financial regulation and solving the model in general equilibrium. This last feature is particularly important for our novel channel; richer structural corporate finance models with agency frictions, such as Nikolov and Whited (2014), are instead typically solved in partial equilibrium.

\section{Literature review}

Thakor (2014) surveys the vast literature on the effects of bank capital and changes in capital requirements, and notes that much of the work on the effects of bank capital tends to be qualitative or abstracts from general equilibrium. For example, Berger and Bouwman (2013) show that, in the cross-section, large and medium banks with higher capital ratios gain market share during financial crises. This cannot be a potential benefit of increasing capital requirements, since not everyone can gain market share in general equilibrium. Similarly, Mehran and Thakor (2011) show that better-capitalized banks are more valuable to acquirers, in contrast to theories that predict that they are equally valuable as less-well-capitalized banks (Modigliani and Miller 1958) or less valuable (Diamond and Rajan 2001). Likewise, their empirical results are identified in the cross-section of banks abstracting from general equilibrium effects. 
A more recent and growing literature has embedded the analysis of capital requirements into quantitative general equilibrium models. This literature includes Van den Heuvel (2008), Christiano and Ikeda (2013), Corbae and D'Erasmo (2014), Nguyễn (2014), Gertler, Kiyotaki and Prestipino (2016), Begenau and Landvoigt (2017), Davydiuk (2017), Dempsey (2017), and Begenau (2018). Egan, Hortaçsu and Matvos (2017) develop a structural model of the US banking sector including runs and partial deposit insurance and argue that capital requirements should be at least $18 \%$ to avoid bank runs.

A related paper by Allen et al. (2018) studies the effect of government guarantees on banks' choices of liquidity and investments in risky projects. Both our paper and that of Allen et al. (2018) point out that higher risk-taking can be a good consequence of financial regulation. In their paper, more risk-taking by banks is associated with greater liquidity provision. In our paper, more risk-taking by firms has a positive impact, in general, on employment and output.

Our approach for modeling firms' risk builds on Quadrini (2017), who also emphasizes the role of bank liabilities for insurance purposes. ${ }^{3}$ There are, however, two main differences. First, he focuses mainly on banks' risk-taking and crises, whereas our focus is on the impact of financial regulation on non-financial firms' risk-taking. ${ }^{4}$ Second, we extend his model so that we can reinterpret the agents subject to idiosyncratic risk as firms run by managers who cannot diversify away idiosyncratic risk because of an agency friction. This extension facilitates the welfare analysis and the comparison of the model with the data, and it represents a separate contribution of our paper. Indeed, the firms' building block of our model can be used to study other questions at the intersection of corporate finance and macroeconomics.

Firms in our model use only deposits to self-insure against their idiosyncratic shocks. In principle, other safe assets not tied directly to banks' balance sheets and capital regulation, such as Treasury securities, could also be used for the same purposes. However, we argue that the logic of our results is not affected by this consideration. First, government debt does not satiate the demand for safe assets (i.e., liquidity premia on safe assets are positive; see Krishnamurthy and Vissing-Jorgensen, 2012 and Nagel, 2016), thereby leaving a role for privately-supplied safe securities. Second, even if the importance of deposits has decreased in recent decades, they are still one of the largest components of the privately-supplied safe assets - if not the largest (Gorton, Lewellen and Metrick, 2012). In addition, deposits in our model can also be mapped to other bank liabilities in the data, strengthening this consideration. Third, the non-financial private sector values the liquidity services provided

\footnotetext{
${ }^{3}$ The approach used by Quadrini (2017) at modeling firms' risk builds on Arellano, Bai and Kehoe (2011).

${ }^{4}$ Dindo, Modena and Pelizzon (2018) derive a demand for banks' liabilities for insurance purposes similar to Quadrini (2017) and ours (although in a continuous-time model), but the regulation of intermediaries that they study always reduces welfare.
} 
by deposits more than those provided by government debt, as shown by Van den Heuvel (2018).

This paper is also related to a literature that studies financial intermediaries as suppliers of safe assets, such as Stein (2012), Magill, Quinzii and Rochet (2016), and Diamond (2016). This literature builds on the ideas of Gorton and Pennacchi (1990) and Dang et al. (2017), in which the debt of banks is riskless to enhance its liquidity value or to overcome an informational friction. Bank debt is valuable in our model for a related but slightly different reason: there is a demand for securities that are uncorrelated with the idiosyncratic risk of firms. Some of these papers also perform policy analyses in models with deposits in the utility function (e.g., the monetary policy tools discussed by Stein, 2012). While the theoretical results of these papers are likely not affected by our main message, the corresponding quantitative policy stance might need to be tilted by imposing stricter limits on financial intermediaries' liabilities.

Our paper relates to a large literature on firms' exposure to idiosyncratic risks. Smith and Stulz (1985) and Froot, Scharfstein and Stein (1993) derive theories in which firms do not completely hedge away idiosyncratic risks because external financing is costly. Minton and Schrand (1999) provide empirical evidence that firms that are more exposed to idiosyncratic risk invest less and have higher costs of external financing than other firms, consistent with an inability or unwillingness to completely insure against idiosyncratic shocks. In this setting, idiosyncratic shocks are costly to the firm. In addition, we build on the results of Panousi and Papanikolaou (2012) and Glover and Levine (2015, 2017) and we assume that firms are run by managers that are subject to the idiosyncratic risk of the firm they run. Thus, as pointed out by Panousi and Papanikolaou (2012), risk aversion of managers plays a role in shaping firm decisions. In our model, this implies that deposits provide insurance against the idiosyncratic risk, consistent with the finding of Bates, Kahle and Stulz (2009) of a rising trend in firms' cash holdings since the 1980s that they attribute in large part to an increasing precautionary motive.

More generally, our work is part of a broader literature that relates financial intermediaries, firms' idiosyncratic risk, and the labor market. Bacchetta, Benhima and Poilly (forthcoming) show a negative relation between corporate cash holdings and employment in the data, which they rationalize with external liquidity shocks to firms. Bigio (2010) and Jermann and Quadrini (2012) study how firms' financial frictions affect the macroeconomy, including labor demand. Donaldson, Piacentino and Thakor (forthcoming) analyze a model in which households borrow from banks and the possibility of default interacts with the firms' output and employment. Herskovic et al. (2016) rationalize the pricing of shocks to firms' idiosyncratic volatility using a model in which the shocks are transmitted to households 
through the labor market.

Finally, Li, Rocheteau and Weill (2012) also show that the liquidity premium might not be a sufficient statistic for policy analysis. However, their focus is very different; they study open market operations in a model with the threat of fraudulent assets.

\section{Model}

\subsection{Environment}

Time is discrete and infinite. There are four main players in the economy: firms run by managers, banks, households, and the government. There is also a bank-financed production sector, representing the assets in which banks invest, but it will play a minor role. Before presenting the details of the model, we briefly summarize the main structure.

We follow Quadrini (2017) in assuming that firms are subject to idiosyncratic risk and hold deposits for precautionary reasons, but we depart somewhat from his model. In particular, each firm is run by a risk-averse manager who acts in her own interest because of an agency friction. This friction motivates the manager's holding of an undifferentiated stake in the firm she runs, and thus an exposure to firm-specific idiosyncratic risk. In contrast, firms' owners (i.e., households) fully diversify away the idiosyncratic risk by holding equity stakes in all firms. These assumptions are motivated by the results of Panousi and Papanikolaou (2012), who document that managerial compensation affects firms' investments in response to idiosyncratic risk, and Glover and Levine (2015, 2017), who calibrate structural models of firm investment and show that managers respond more to firm-specific shocks in comparison to what shareholders would choose in the absence of agency frictions.

We model firms using a simpler approach than in typical structural corporate finance models with agency frictions, such as Nikolov and Whited (2014), for two reasons. First, our approach allows us to keep the firm side of the model tractable and focus on financial regulation. Second, we can easily solve the model in general equilibrium, which is crucial for our results. Many papers in the corporate finance literature model firms' dynamics in rich partial equilibrium settings, and extending those frameworks to general equilibrium would cloud our message.

Banks collect deposits from firms, invest in a bank-financed sector, and are subject to idiosyncratic shocks that make a fraction of them insolvent. Deposits at insolvent banks are made whole by the government through deposit insurance.

Households consume, supply labor, and own firms and banks. We will impose some

parameter restrictions so that the objective of financial regulation will be solely that of 
maximizing the welfare of households, without any consideration for the welfare of managers.

We first convey our results in a simple model that includes only the main elements. In particular, the simple model has no aggregate risk, linear utility from households' consumption, exogenous risk of banks investments, and an ad-hoc rule to determine firms' dividends. We then relax these assumptions in the quantitative model of Section 5.

\subsubsection{Firms and managers}

There is a continuum of firms that are owned by households. Each firm is run by a manager who behaves in her own interest because of an agency friction and owns an equity stake in the firm. ${ }^{5}$

The role of the manager is to choose the amount of labor $l_{t}^{i}$ that is hired every period by the firm. The total output produced by the firm is $z_{t+1}^{i} l_{t}^{i}$, where $z_{t+1}^{i}$ is the firm's productivity. The productivity $z_{t+1}^{i}$ is subject to an idiosyncratic shock realized at the beginning of $t+1$. Crucially, $z_{t+1}^{i}$ is realized after the manager has chosen the labor input $l_{t}^{i}$ and has committed to pay the wage bill $w_{t} l_{t}$, where $w_{t}$ is the wage. For future reference we will denote $\bar{z}$ to be the average realization of the shock: $E_{t}\left\{z_{t+1}^{i}\right\}=\bar{z}$.

In addition, the firm holds deposits $d_{t}^{i}$ at time $t$ in the banking system, which earn a return $R_{t}^{d}$ at $t+1$. The government provides full deposit insurance, so deposits are safe. At time $t$, the manager takes the deposits $d_{t}^{i}$ as pre-determined.

At the beginning of $t+1$, the total wealth available to the firm is given by

$$
x_{t+1}^{i}=\left(z_{t+1}^{i}-w_{t}\right) l_{t}^{i}+R_{t}^{d} d_{t}^{i}
$$

where the first term on the right-hand side denotes the profits obtained by hiring workers (which can be negative if the productivity shock $z_{t+1}^{i}$ is low) and the second term denotes the gross return on deposits.

A fraction $\alpha$ of the wealth $x_{t+1}^{i}$ is paid out as dividends, and the remaining fraction $1-\alpha$ is retained by the firm, where $\alpha$ is an exogenous parameter (we will endogenize $\alpha$ in the full model of Section 5). Thus, deposits evolve according to $d_{t+1}^{i}=(1-\alpha) x_{t+1}^{i}$ or, using (1),

$$
d_{t+1}^{i}=(1-\alpha)\left[\left(z_{t+1}^{i}-w_{t}\right) l_{t}^{i}+R_{t}^{d} d_{t}^{i}\right]
$$

In this simple model in which $\alpha$ is exogenous, all results are unchanged if we make such a

\footnotetext{
${ }^{5}$ The contract between the firm and the manager is imposed exogenously but we could derive it endogenously as the best contract that makes the manager unwilling to divert resources away from the firm for personal use. However, this would complicate the exposition and would not affect the results.
} 
parameter time varying and firm-specific, but we instead keep it constant to simplify the exposition. ${ }^{6}$. Note that $\alpha$ is not chosen by the manager and, in this sense, can be understood as a part of the contract between the manager and the shareholders.

We parametrize the equity stake of the manager by $\kappa$, so that manager's dividends are $\alpha \kappa x_{t+1}^{i}$ and dividends paid to shareholders (i.e., to households) are $\alpha(1-\kappa) x_{t+1}^{i}$. The manager consumes all her dividends each period, ${ }^{7}$ so her consumption $c_{t+1}^{i}$ is

$$
c_{t+1}^{i}=\alpha \kappa\left[\left(z_{t+1}^{i}-w_{t}\right) l_{t}^{i}+R_{t}^{d} d_{t}^{i}\right],
$$

which produces a utility value $\theta \log c_{t+1}^{i}$, where $\theta>0$ parametrizes the manager's utility. Dividends paid to shareholders (i.e., households) are given by

$$
\pi_{t+1}^{i}=\alpha(1-\kappa)\left[\left(z_{t+1}^{i}-w_{t}\right) l_{t}^{i}+R_{t}^{d} d_{t}^{i}\right]
$$

We can thus formalize the problem of the manager. The manager solves

$$
V_{t}^{m}\left(d_{t}^{i}\right)=\max _{l_{t}^{i}} \beta^{m} E_{t}\left\{\theta \log c_{t+1}^{i}+V_{t+1}^{m}\left(d_{t+1}^{i}\right)\right\}
$$

subject to $(2)$ and $(3)$, and where $\beta^{m} \in(0,1)$ is the discount factor of the manager and $E_{t}$ denotes the expectation with respect to the idiosyncratic productivity shock $z_{t+1}^{i}$.

Since the manager hires workers $l_{t}^{i}$ before the realization of the productivity $z_{t+1}^{i}$, and thus chooses the wage bill $w_{t} l_{t}^{i}$ before knowing $z_{t+1}^{i}$, the manager's consumption fluctuates over time. For any given choice of $l_{t}^{i}$, a high value of $z_{t+1}^{i}$ implies that firms' wealth $x_{t+1}^{i}$, dividends $(1-\alpha) x_{t+1}^{i}$, and manager's consumption $c_{t+1}^{i}$ will be high as well, and vice versa.

Crucially, the manager has the ability to control the volatility of her consumption $c_{t+1}^{i}$ through the choice of $l_{t}^{i}$. In particular, this volatility is increasing in $l_{t}^{i}$. In principle, the manager can choose $l_{t}^{i}=0$, which would imply a deterministic consumption $c_{t+1}^{i}=\alpha \kappa R_{t}^{d} d_{t}^{i}$; however, the manager will find it optimal to hire some workers, $l_{t}^{i}>0$, and thus to be exposed to the idiosyncratic risk.

Our model is consistent with some of the evidence in Opler et al. (1999). Riskier cash flow (i.e., higher variance of $z_{t+1}^{i}$ ) implies that the firm is willing to hold more cash. In addition, firms that do well (i.e., firms hit by a sequence of good values of $z_{t+1}^{i}$ ) accumulate cash internally, and firms that experience losses (i.e., firms with bad realizations of $z_{t+1}^{i}$ )

\footnotetext{
${ }^{6}$ More precisely, we could replace $\alpha$ with $\alpha_{t}^{i}$, subject to the restriction that the average value is the same in the cross section, that is, $\int \alpha_{t}^{i} d i=\alpha$ for all $t$.

${ }^{7}$ This assumption is without loss of generality because of some parameter restrictions that we will impose in Section 3.3.
} 
experience decreases in cash.

After solving the problem of managers, we will impose parametric restrictions on $\theta$ and $\kappa$ which imply that managers' consumption is arbitrarily small and all dividends will be paid to shareholders, while at the same time preserving the implications of the agency friction on firms' behavior.

We will derive our theoretical results under a general specification of the stochastic process for $z_{t+1}^{i}$. However, in the simulations, we will use the following functional form: $z_{t+1}^{i}=1 / p_{z}$ with probability $p_{z} \in(0,1)$, and $z_{t+1}^{i}=0$ with probability $1-p_{z}$. This implies that $\bar{z} \equiv E_{t}\left\{z_{t+1}^{i}\right\}$ will be normalized to one.

\subsubsection{Banks and bank-financed firms}

Banks live for a single period: each bank is set up at time $t$ and is liquidated at the beginning of time $t+1 .^{8}$ Each newly-created bank receives an amount $n_{t}$ of net worth from its shareholders (i.e., households). Then, the bank collects deposits $d_{t}$ and uses the resources $n_{t}+d_{t}$ to purchase physical capital $k_{t}$. In the economy as a whole, capital accumulates endogenously, similar to a standard neoclassical growth model.

At the beginning of $t+1$, each bank is hit by an idiosyncratic quality shock $\varepsilon$, with $E\{\varepsilon\}=1$. This shock captures the fact that some banks experience higher or lower losses on their loans and investments in comparison to the average bank in the economy. Formally, after the shock, the stock of capital held by a particular bank is $\varepsilon k_{t}$; the total stock of capital in the banking sector as a whole is unchanged, because the shock $\varepsilon$ is idiosyncratic. Banks lend the physical capital $\varepsilon k_{t}$ to bank-financed firms, which then return the undepreciated fraction $1-\delta$ of the physical capital plus a return $r_{t+1}$ to the banks. Banks' profits are given by the cash flow $\varepsilon k_{t}\left(1-\delta+r_{t+1}\right)$ net of the repayment $R_{t}^{d} d_{t}$ to depositors, where $R_{t}^{d}$ is the gross return on deposits. Profits are bounded below by a limited liability constraint; that is, banks with negative profits pay zero to shareholders.

Banks face a capital requirement $\zeta$ that limits their ability to raise deposits. That is, their equity ratio $n_{t} / k_{t}$ must be weakly larger than the regulatory requirement $\zeta$.

In this simple model, we do not allow banks to choose the riskiness of the assets they invest in. However, in Section 5, we introduce these features, in line with the analyses of Van den Heuvel (2008) and Begenau (2018).

\footnotetext{
${ }^{8}$ This assumption is made without loss of generality because our model does not include adjustment costs on banks' size nor costs to raise equity.
} 
We can now formalize the problem of banks. Given $n_{t}$, the bank's problem is

$$
\begin{aligned}
\max _{k_{t}, d_{t}} & \int\left\{\varepsilon k_{t}\left(1-\delta+r_{t+1}\right)-R_{t}^{d} d_{t}\right\}^{+} d F(\varepsilon) \\
\text { s.t. } & \\
k_{t} & =d_{t}+n_{t} \\
& n_{t} \geq \zeta k_{t}
\end{aligned}
$$

where $(7)$ is the budget constraint, (8) reflects the capital requirement, $\{\cdot\}^{+}=\max \{\cdot, 0\}$ is the positive part of bank's profits, and $F(\cdot)$ is the CDF of banks' idiosyncratic productivity shocks. Our theory results holds for a generic $F(\cdot)$, but for our simulations we will assume that $\varepsilon$ is $\log$-normally distributed with mean $E(\varepsilon)=1$ and variance $\sigma^{2}$; i.e., $\log \varepsilon \sim \mathbb{N}\left(-\frac{1}{2} \sigma^{2}, \sigma^{2}\right)$. The deposits at banks that receive a low value of the productivity shock $\varepsilon$, such that $\varepsilon k_{t}\left(1-\delta+r_{t+1}\right)<R_{t}^{d} d_{t}$, are fully repaid to depositors thanks to the deposit insurance intervention.

When shareholders invest in banks' equity, they invest in a mutual fund that diversifies its holdings of equity over all banks in the economy. The return on equity $R_{t+1}^{n}$ is given by

$$
R_{t+1}^{n}=\frac{1}{n_{t}} \int\left\{\varepsilon k_{t}\left(1-\delta+r_{t+1}\right)-R_{t}^{d} d_{t}\right\}^{+} d F(\varepsilon)
$$

Equation (9) implies that $\underline{\varepsilon}_{t+1}$, the highest value of $\varepsilon$ at which banks default on their depositors, is implicitly defined as:

$$
R_{t}^{d} d_{t}=\underline{\varepsilon}_{t+1} k_{t}\left(1-\delta+r_{t+1}\right)
$$

From a mechanical perspective, the problem of banks can be solved as follows. Because in equilibrium the return on deposits will be less than the return on banks' capital, the capital requirement (8) is always binding. As a result, banks' technology is constant returns to scale. Given $n_{t}$, (8) can be used to compute the size $k_{t}$ of the banks' assets, and then the budget constraint (7) can be used to solve for deposits $d_{t}$. Finally, the equilibrium value of $n_{t}$ is determined such that (10) holds, given the return on equity demanded by banks' shareholders in equilibrium.

Subsidized deposit insurance creates an incentive for banks to lower their lending rate $r_{t+1}$, thereby increasing the amount of physical capital in the economy. The logic of this result is the usual combination of limited liability and a lack of responsiveness of the deposit rate $R_{t}^{d}$ due to deposit insurance. The overaccumulation of capital due to the distortion of subsidized deposit insurance entails a welfare loss. 
We close this section by describing the problem of bank-financed firms. These firms rent capital $k_{t}$ from banks and use it for production, according to the production function $A k_{t}^{\gamma}$, with $\gamma \in(0,1)$ and $A>0$. Thus, their profits $\pi_{t+1}^{b f}$ (where $b f$ stands for "bank-financed") are obtained by maximizing

$$
\pi_{t+1}^{b f}=\max _{k_{t}} A k_{t}^{\gamma}-r_{t+1} k_{t},
$$

which implies the first-order condition

$$
A \gamma k_{t}^{\gamma-1}=r_{t+1}
$$

The profits $\pi_{t+1}^{b f}$ are positive because bank-financed firms use a decreasing-return-to-scale technology, and they are distributed lump-sum to households.

\subsubsection{Households}

Households are infinitely-lived agents with linear utility of consumption $c_{t}$ and convex disutility of labor supply $l_{t}$. This quasi-linear specification allows us to easily characterize their choices, but we will use a more general utility function in the quantitative model of Section 5. Households supply the labor used by firms and the equity to banks, and they earn the profits generated by the firms run by managers, the banks, and the bank-financed firms.

Households' utility is given by

$$
\sum_{t=0}^{\infty} \beta^{t} u\left(c_{t}, l_{t}\right)=\sum_{t=0}^{\infty} \beta^{t}\left[c_{t}-\beta \chi \frac{l_{t}^{1+\frac{1}{\eta}}}{1+\frac{1}{\eta}}\right]
$$

where $\chi>0, \eta>0$, and $\beta \in(0,1)$. Households choose labor at time $t$, but do not provide that labor until the beginning of period $t+1$ when production actually occurs; thus we discount the disutility of labor chosen at $t$ with and additional $\beta$ in equation (13).

A household that starts with wealth $a_{t}$ solves the problem

$$
V_{t}^{h}\left(a_{t}\right)=\max _{c_{t}, l_{t}, n_{t}} c_{t}-\beta \chi \frac{l_{t}^{1+\frac{1}{\eta}}}{1+\frac{1}{\eta}}+\beta V_{t+1}^{h}\left(a_{t+1}\right)
$$

subject to the budget constraint

$$
c_{t}+n_{t} \leq a_{t}
$$

and to an upper bound on the amount of hours worked, $l_{t} \leq \bar{l}$. Wealth at $t+1$ is given by

$$
a_{t+1}=w_{t} l_{t}+n_{t} R_{t+1}^{n}+\int \pi_{t+1}^{i} d i+\pi_{t+1}^{b f}-T_{t+1} .
$$


At time $t$, the household chooses how to allocate its wealth $a_{t}$ between consumption $c_{t}$ and investment in bank equity $n_{t}$, and it chooses the labor supply $l_{t}$ taking as given the wage $w_{t}$. At $t+1$, the wealth is the sum of its labor income $w_{t} l_{t}$, the gross return on banks' equity $n_{t} R_{t+1}^{n}$, and the profits $\int \pi_{t+1}^{i} d i$ and $\pi_{t+1}^{b f}$ distributed by manager-run firms and bank-financed firms, net of lump-sum taxes $T_{t+1} \cdot{ }^{9}$

Finally, note that households' choice of $n_{t}$ affects the accumulation of physical capital $k_{t}$, given firms' deposits $\int d_{t}^{i} d i$ and banks' budget constraint (7).

\subsubsection{Government}

The government taxes households in order to ensure that depositors at failed banks at the beginning of $t+1$ are made whole. The government seizes output at failed banks (who return zero to their equity holders) to partially defray the expenses of paying back depositors.

The total amount of tax to be collected is

$$
T_{t+1}=\int_{-\infty}^{\underline{\varepsilon}_{t+1}}[\underbrace{R_{t}^{d} d_{t}}_{\text {owed to depositors }}-\underbrace{\varepsilon k_{t}\left(1-\delta+r_{t+1}\right)}_{\text {collected from banks }}] d F(\varepsilon) .
$$

where $R_{t}^{d} d_{t}$ is the amount owed to depositors, and $\varepsilon k_{t}\left(1-\delta+r_{t+1}\right)$ for $\varepsilon<\underline{\varepsilon}_{t+1}$ denotes the assets of failed banks.

\subsection{Equilibrium definition}

Given initial conditions $d_{0}^{i}$ for all $i$ and $a_{0}$, and exogenous stochastic processes for $\left\{z_{t}^{i}\right\}$ and $\{\varepsilon\}$, an equilibrium is a collection of firm policies, bank policies, households policies, and government taxes such that

1. Firms' deposits $d_{t}^{i}$, managers' consumption $c_{t}^{i}$, and managers' choice for labor demand $l_{t}^{i}$ solve (5);

2. Banks' choices for capital $k_{t}$ and deposits $d_{t}$ solve their problem (6);

3. Households' choices for supply of labor $l_{t}$ and net worth $n_{t}$ maximize their utility (13).

4. The government taxes households lump-sum and uses the proceeds to pay depositors at failed banks according to equation (16).

\footnotetext{
${ }^{9}$ Note that we allow households to choose only investments in banks' equity claims because that is a key element of our model. In principle, we could enrich households' portfolio choice by allowing them to trade claims on firms' dividends; however, that would not change any of the results and would simply add more notation because of our representative household assumption.
} 
5. The wage $w_{t}$ and the return on deposits $R_{t}^{d}$ clear the labor and deposit markets, respectively.

The aggregate resource constraint will hold by Walras' law. Nonetheless, we state it to clarify the mechanics of the model:

$$
c_{t}+k_{t}-(1-\delta) k_{t-1} \leq \bar{z} l_{t-1}+A k_{t-1}^{\gamma}
$$

where $l_{t-1}=\int l_{t-1}^{i} d i$ is total labor. The resources produced each period are the output $\bar{z} l_{t-1}$ of managers-run firms and the output $A k_{t-1}^{\gamma}$ of bank-financed firms; recall that the output of managers-run firms depends on labor choices made at $t-1$. These resources are used for consumption $c_{t}$ or to invest in the stock of capital $k_{t}$, net of the undepreciated stock $(1-\delta) k_{t-1}$ from the previous period, as in the standard growth model.

\subsection{Agents' choices and aggregation}

This section discusses the optimality conditions that characterize the choices of firms, households, and banks. We show that firms' choices can be easily aggregated despite the heterogeneity in their wealth. In addition, we impose a parametric restriction so that the importance of managers vanishes for welfare calculations without affecting the implications of the agency friction. That is, we will be able to solve for the optimal financial regulation by focusing exclusively on households' welfare, without any consideration for mangers' welfare.

We begin the analysis by discussing the solution to the managers' problem. The following proposition greatly simplifies the analysis by allowing us to aggregate easily across managers. All proofs are in Appendix A.

Proposition 1. (Managers and firms' labor demand) Manager i's optimal choice of labor is $l_{t}^{i}=\phi_{t} d_{t}^{i}$, where $\phi_{t}$ is independent of $d_{t}^{i}$ and satisfies the following first-order condition:

$$
0=E_{t}\left\{\frac{z_{t+1}^{i}-w_{t}}{\left(z_{t+1}^{i}-w_{t}\right) \phi_{t}+R_{t}^{d}}\right\},
$$

In our model, individual firms will grow and shrink as they receive different sequences of idiosyncratic shocks. However, a firm's labor demand $l_{t}^{i}$ is proportional to its deposits $d_{t}^{i}$, and thus the firm-size distribution does not affect aggregate variables.

The first-order condition (17) governs firms' decisions to hire workers. The firm's labor demand is lower in comparison to an economy in which the manager would be able to diversify away her exposure to the firms' idiosyncratic risk. That is why we refer to the willingness of 
firms to hire workers as the "good" risk-taking decision, because any force that creates an incentive for firms to hire more workers brings the economy closer to the first best.

The result of Proposition 1 is independent of the equity stake $\kappa$ of the manager, provided that $\kappa>0$. To simplify the welfare analysis, we impose that $\kappa$ is arbitrarily small so that consumption of managers is negligible. Under this assumption, we can perform welfare analysis of capital requirements simply by studying the welfare of households. We also impose some restrictions on $\theta$ (i.e., the parameter that affects the utility of managers). However, this is done mostly for technical reasons, that is, to make sure that the managers' problem is well-behaved even in the limit as $\kappa$ is small

Proposition 2. (Parameter restrictions and welfare) Let $\theta=\eta_{1} \kappa^{\eta_{2}}$, where $\eta_{1}$ and $\eta_{2}$ are any two constants satisfying $\eta_{1}, \eta_{2}>0$. If $\kappa \downarrow 0, \kappa>0$, manager $i$ 's optimal choice in Proposition 1 is not affected, manager $i$ 's consumption converges to $c_{t+1}^{i} \downarrow 0$, and manager's value function converges to $V_{t}^{m} \downarrow 0$. In addition, profits distributed to households, defined in (4) become

$$
\lim _{\kappa \downarrow 0, \kappa>0} \pi_{t+1}^{i}=\alpha\left[\left(z_{t+1}^{i}-w_{t}\right) \phi_{t}+R_{t}^{d}\right] d_{t}^{i},
$$

and the economy-wide welfare function $W$ is equal to the value function of households:

$$
W=V_{0}^{h}\left(a_{0}\right)
$$

The key result of Proposition 2 is that the importance of managers vanishes for welfare purposes (i.e., their consumption converges to zero) without affecting the key first-order condition that governs their labor demand, (17). The implication of Proposition 2 is that we can just focus on the welfare of households when evaluating financial regulation. That is, we can ignore the welfare of managers when we determine the optimal financial regulation, even though the model exhibits a behavior driven by an agency friction.

To complete the analysis of the firms' building block of the model, we aggregate labor demand and the law of motion of deposits across firms. As noted before, labor demand does not depend on the distribution of deposits across firms because deposits $d_{t}^{i}$ do not enter the first-order condition (17). Thus, total labor demand $l_{t}$ is

$$
\begin{aligned}
l_{t} & =\int l_{t}^{i} d i \\
& =\phi_{t} d_{t},
\end{aligned}
$$

where the second line uses the result $l_{t}^{i}=\phi_{t} d_{t}^{i}$ from Proposition 1 and defines $d_{t}$ to be total deposits across firms, $d_{t}=\int d_{t}^{i} d i$. Similarly, we can easily aggregate over firms' law of 
motion for deposits. To do so, we first impose the restriction

$$
\alpha=1-\beta
$$

This assumption allows us to obtain a benchmark result in which Modigliani-Miller holds for banks if we shut down all shocks and deposit insurance (i.e., the return on deposits and banks equity are the same; see Appendix B). Then, using (2) and (19), the law of motion of aggregate deposits $d_{t}$ is

$$
d_{t+1}=\beta\left[\left(\bar{z}-w_{t}\right) \phi_{t}+R_{t}^{d}\right] d_{t},
$$

where $\bar{z}$ denotes the mean of the idiosyncratic firm productivity $z_{t+1}^{i}$.

Next, we turn to the problem of households. The linear utility from consumption implies that their value function is linear as well, that is, $\left(V^{h}\right)^{\prime}(a)=1$. Thus, their labor supply curve is given by

$$
w_{t}=\chi\left(l_{t}\right)^{\frac{1}{\eta}}
$$

and the supply of banks' net worth $n_{t}$ is fully elastic (i.e., they are willing to supply any amount) provided that the return on equity $R_{t+1}^{n}$ satisfies

$$
R_{t+1}^{n}=\frac{1}{\beta}
$$

The choices of banks are given by (7), (8) and

$$
\int_{\underline{\varepsilon}_{t+1}}^{\infty} \varepsilon\left(1-\delta+r_{t+1}\right) d F(\varepsilon)=\zeta R_{t+1}^{n}+(1-\zeta) \operatorname{Pr}\left\{\varepsilon \geq \underline{\varepsilon}_{t+1}\right\} R_{t}^{d},
$$

which follows from (9) combined with (7) and (8). Equation (23) equalizes the benefits and costs of purchasing an extra dollar of physical capital for a bank. The marginal benefit is the gross return $\varepsilon\left(1-\delta+r_{t+1}\right)$, only in the states in which the bank is not in default, that is, for $\varepsilon \geq \underline{\varepsilon}_{t+1}$. The marginal cost of financing the purchase corresponds to the cost of raising more deposits and more equity. A fraction $\zeta$ of the purchase requires equity, for which households require a return $R_{t+1}^{n}$. The remaining fraction $1-\zeta$ can be financed with deposits, which in turn requires a return $R_{t}^{d}$; the bank internalizes the cost of deposits only in the states of the world in which it remains solvent, which happens with probability $\operatorname{Pr}\left\{\varepsilon \geq \underline{\varepsilon}_{t+1}\right\}$.

We conclude this section by showing that our model generates a premium on the return on deposits which is equal to their marginal private value. We focus on the steady state, as we do for most the rest of our theoretical analysis in Section 4, and denote steady-state 
values by dropping the time subscript.

Proposition 3. (Deposit premium) Assume that $\operatorname{Var}\left(z_{t+1}^{i}\right)>0$. In steady state, the deposit premium is

$$
\begin{aligned}
0<\frac{1}{\beta}-R^{d} & =\int\left[\left.\left(E_{t}\left\{z_{t+1}^{i}\right\}-w\right) \frac{\partial l_{t}^{i}}{\partial d_{t}^{i}}\right|_{w \text { fixed }}\right] d i \\
& =(\bar{z}-w) \phi
\end{aligned}
$$

where the right-hand side of (24) denotes the marginal private value of deposits.

The deposit premium is positive because deposits provide insurance to firms' managers against the exposure to idiosyncratic risk. Such a premium is then equal to the marginal private value of deposits (i.e., the right-hand side of equation (24)). To understand this expression, consider the following. If each firm began time $t$ with an additional $\$ 1$ dollar of deposits, managers would take more risk (i.e., hire more workers) and firm $i$ would earn a

profit $z_{t+1}^{i}-w_{t}$ per additional worker hired. Such profits would then be valued by households according to their constant unitary marginal utility of consumption.

Crucially, the marginal private value of deposits is computed by taking the wage $w$ as given. In the next section, we show that a regulator that sets the optimal capital requirement should instead take into account the general equilibrium response of the wage, which gives rise to a wedge between the private and social value of deposits.

\section{Theoretical results}

This section derives the main theoretical results of the paper. We first study the effects of capital requirements on firms' good risk-taking (Section 4.1) and banks' bad risk-taking (Section 4.2). In Section 4.3 we examine the welfare implications of ignoring the general equilibrium effects that we emphasize.

Throughout this section we illustrate the theory with numerical examples to highlight how good risk-taking and bad risk-taking are traded off in the determination of the optimal capital requirements. Later in Section 5 we calibrate a quantitative model to better estimate the magnitudes of the effects we describe in this section.

\subsection{Capital requirements and good risk-taking}

This section presents the main result about the interaction between capital requirements and firms' good risk-taking. The effects of modifying capital requirements differ dramatically 

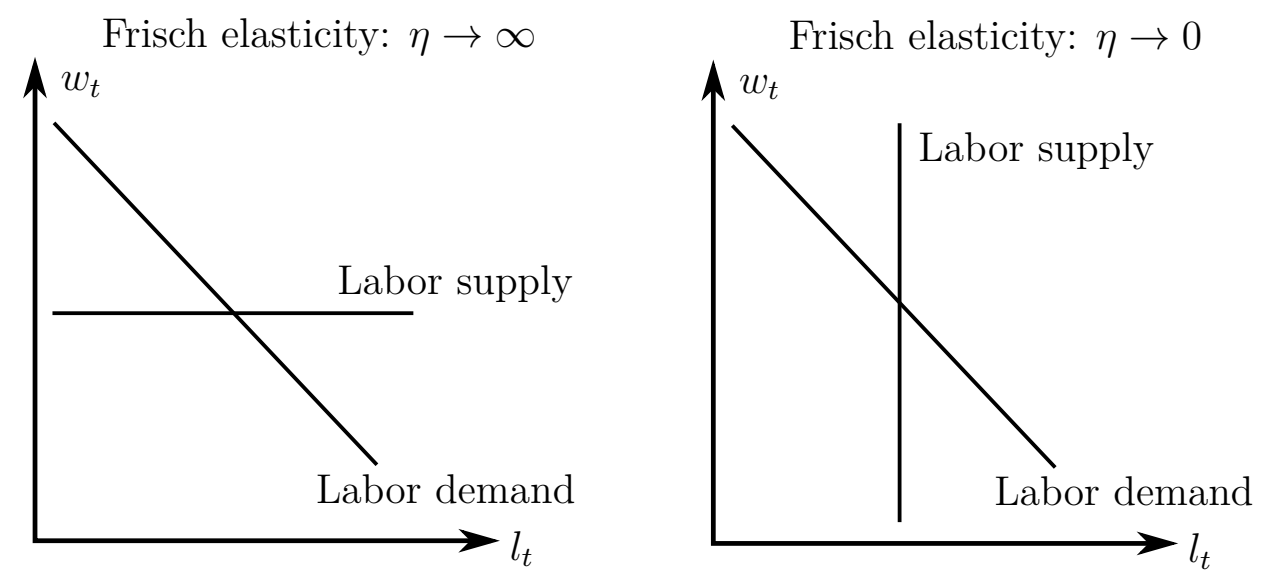

Figure 1. Equilibrium in the labor market. Left panel: the labor supply curve is infinitly elastic and thus pins down the wage. Right panel: the labor supply curve is inelastic and thus pins down the equilibrium value of employment.

depending on how firms' input prices - in our model, wages - adjust in response to the policy change.

In this simple model, we show next that the equilibrium response of wages to policy changes depends on the Frisch elasticity of labor supply. This elasticity is defined as the percentage change in households' labor supply in response to a $1 \%$ change in the wage, keeping consumption constant. Using the first-order condition of households (21), we obtain that

Frisch elasticity of labor supply $=\eta$

(recall that $\eta$ is one of the parameters that affects the disutility of labor).

To further clarify the role of the Frisch elasticity of labor supply, Figure 1 plots the demand and supply in the labor market in two extreme cases. In the left panel, the Frisch elasticity of labor supply is $\eta \rightarrow \infty$ (i.e., labor supply is fully elastic and households have linear disutility from labor). In this case, the wage is essentially fixed because the households' first-order condition (21) implies $w_{t}=\chi$. Thus, if firms demand more inputs in response to policy changes, the wage does not change, and the effect of financial regulation on employment is maximal. The right panel plots the other extreme case, in which the Frisch elasticity is $\eta \rightarrow 0$ (i.e., labor supply is fixed). In this case, financial regulation produces an impact only on wages $w_{t}$ and has no affect on employment $l_{t}$.

In the rest of this section, we formalize the above results and then provide an illustrative example. We maintain our focus on the two extreme cases with fully elastic labor supply (i.e., $\eta \rightarrow \infty$ ) and fixed labor supply (i.e., $\eta \rightarrow 0$ ).

Tightening capital requirements reduces deposits, which in turn makes it harder for 
firms to self-insure against idiosyncratic risk. ${ }^{10}$ In response, firms reduce labor demand. The extent to which this change in labor demand affects equilibrium labor $l_{t}$ depends on the Frisch elasticity of labor supply, $\eta$. If $\eta \rightarrow \infty$ (i.e., labor supply is fully elastic), any change in labor demand is transmitted one-for-one into changes of the equilibrium value of labor, $l_{t}$. If $\eta \rightarrow 0$ (i.e., labor supply is fixed), changes in labor demand produces only changes in the wage, $w_{t}$, but no changes in employment. We summarize this result in the next proposition, focusing on a comparison across steady states and denoting the steady-state value of endogenous variables by dropping the time subscript.

Proposition 4. (Capital requirements and good risk-taking) Assume that there exists a steady-state equilibrium with $l>0$. Then:

- If the Frisch elasticity of labor supply is $\eta \in(0, \infty)$, then $\partial w / \partial \zeta<0$ and $\partial l / \partial \zeta<0$;

- If the Frisch elasticity of labor supply is $\eta \rightarrow \infty$, then $\partial w / \partial \zeta=0$ and $\partial l / \partial \zeta<0$;

- If the Frisch elasticity of labor supply is $\eta \rightarrow 0$, then $\partial w / \partial \zeta<0$ and $\partial l / \partial \zeta=0$.

The first implication of Proposition 4 is that the marginal social value of deposits differs from the marginal private value for all $\eta<\infty .{ }^{11}$ The marginal private value of deposits from the point of view of each firm is implicitly computed by taking the wage as given, but the social value accounts for the fact that the wage may adjust in general equilibrium as the supply of deposits changes. To clarify this point, consider the limiting case in which the labor supply is fixed (i.e., $\eta \rightarrow 0$ ). In this case, an increase in the availability of deposits - due for instance to lower capital requirements - triggers an increase in the wage that exactly offsets the private benefits of the additional deposits. As a result, changing capital requirements does not affect firms' good risk-taking or the equilibrium value of output produced by firms. This is not to say that capital requirements do not produce any effect at all. As we discuss in the next section, even with fixed labor supply, capital requirements affect banks' bad risk-taking and the size of the banking sector.

The second takeaway from Proposition 4 is that the existence of a deposit premium in the data is not sufficient to conclude that deposits have a positive marginal social value. In our model, deposits display a positive premium (i.e., $1 / \beta-R^{d}>0$, as shown in Proposition

\footnotetext{
${ }^{10}$ Lemma 8 in the appendix shows that the steady-state level of deposits, denoted by $d$, satisfies $\partial d / \partial \zeta<0$ for all $\eta \in(0, \infty)$ as well as in the limit as $\eta$ goes to either zero or infinity.

${ }^{11}$ This reasoning requires deposits to be above a certain threshold, which depends on parameters, so that firms hire workers in equilibrium; hence, we require $l>0$ as an assumption of the proposition. If the quantity of deposits is too small, firms cannot insure against idiosyncratic risk and thus they might decide not to hire any workers.
} 


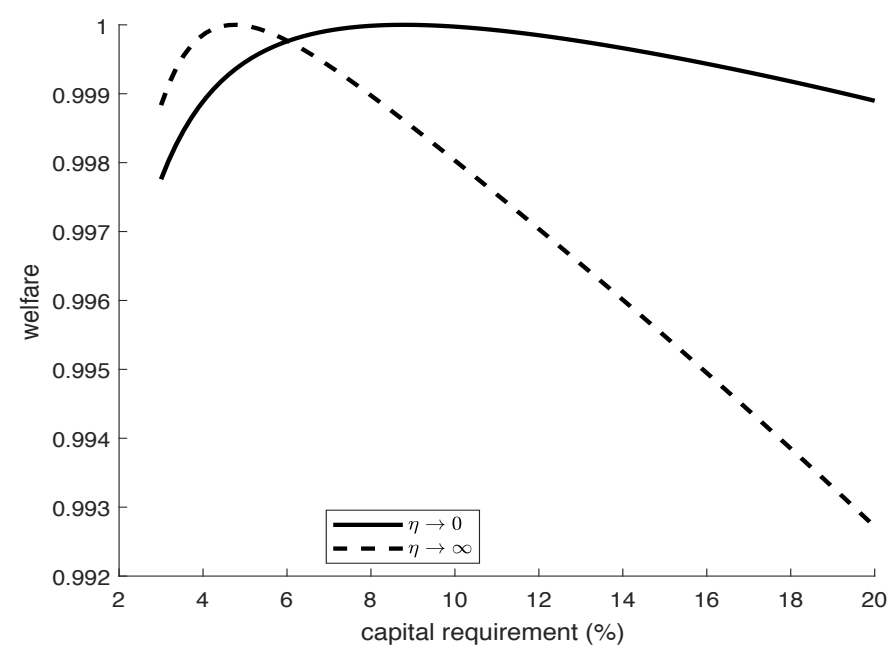

Figure 2. The figure plots total welfare $W(\zeta)$ for values of the capital requirement $\zeta$ ranging from $3 \%$ to $20 \%$, starting from an initial steady-state where $\zeta=8 \%$. Parameter values are $\beta=0.95, p_{z}=0.95, \delta=0.1, A=0.52, \sigma=0.063$, $\chi=0.96$, and $\gamma=0.3$. We choose $A, \sigma$, and $\chi$ to induce a deposit premium of $2 \%$, a default probability of $10 \%$, and an equilibrium consumption value of 1. The dotted line assumes a fully-elastic labor supply (i.e. $\eta \rightarrow \infty$ ); the solid line assumes a fixed labor supply (i.e. $\eta \rightarrow 0$ ), where labor supply is fixed at $\bar{l}=0.555$. Details on these calculations are in Appendix C.

3) even if they have a zero marginal social value. This is because the return on deposits $R^{d}$ is determined by the firms' first-order conditions, which account only for private marginal values. This result stands in contrast with models in which deposits enter the utility function, in which private and social values are the same.

The last key implication of Proposition 4 is that the existence of a wedge between marginal and social values of deposits has crucial implications for determining the optimal capital requirement. If deposits' marginal social value is indeed less than private values, the availability of an additional dollar of deposits is not that important. As a result, capital requirements can be set at a somewhat high level to limit the negative effects of subsidized deposit insurance on banks' bad risk-taking (see next section). In contrast, theories based on deposits in the utility function may overemphasize the welfare importance of deposits and, thus, might suggest a level of capital requirements that is too low, in comparison to the optimal one.

To illustrate this final point, we compare two numerical examples, where the Frisch elasticity is $\eta \rightarrow \infty$ or $\eta \rightarrow 0$. We consider an economy that is initialized at a steady state with a capital requirement $\zeta=8 \%$ and where, at $t=0$, the regulator permanently changes the capital requirement to a different $\zeta$. We then compute welfare $W(\zeta)$ as the economy 
transitions and reaches the new steady state. ${ }^{12}$ Figure 2 plots $W(\zeta)$ for capital requirements ranging from $3 \%$ to $20 \%$. We stress that we have constructed the examples so that both economies with $\eta \rightarrow \infty$ and $\eta \rightarrow 0$ have the same deposit premium of $2 \%$ in the initial steady state with an $8 \%$ capital requirement.

The optimal capital requirement differs substantially between the case $\eta \rightarrow \infty$ and $\eta \rightarrow 0$. With $\eta \rightarrow \infty$ (i.e., fully-elastic labor supply), the private and social value of deposits are equalized, and the the optimal capital requirement is $4.8 \%$. With $\eta \rightarrow 0$ (i.e., fixed labor supply), the marginal social value of deposits is zero, and the optimal capital requirement is much higher, at $8.7 \%$. In addition, the sensitivity of welfare to the capital requirement is much lower in the second case. In the next section, we explain why the optimal capital requirement under fixed labor supply is not too high despite the zero marginal social value of deposits.

\subsection{Capital requirements and bad risk-taking}

We now clarify the effects of capital requirements on banks' choices. First, we highlight that higher capital requirements can either increase or decrease bank lending. This result is essentially the same as in Begenau (2018), but it interacts with firms' good risk-taking in our model. Second, we explain why a capital requirement that is too high is not optimal even if the marginal social value of deposits is zero. Finally, we link all these theoretical results with some empirical evidence that support the existence of a wedge between private and social value of deposits.

Tightening capital requirements produce two effects on the amount of bank lending $k$, which we label the leverage effect and the funding effect. The leverage effect forces banks to be financed proportionally more with equity (i.e., to reduce their leverage). Since equity is more expensive than deposits, banks react by reducing total lending $k$. The funding effect is related to how the deposit rate changes in response to a modification of capital requirements, as noted by Begenau (2018). As tighter capital requirements make deposits more scarce, depositors might be willing to accept a lower return $R^{d}$. Such a lower return reduces the cost for banks to fund an additional dollar of loans, increasing $k$.

The leverage and funding effects are also related to the Frisch elasticity of labor supply, $\eta$. Recall that firms hold deposit to insure against the need to pay wages in the event of a bad productivity shock. Since wages are affected by the Frisch elasticity $\eta$, firms' demand for deposits is tied to this elasticity as well. When the Frisch elasticity is $\eta<\infty$, both the leverage and funding effects are at work. If instead the Frisch elasticity is $\eta \rightarrow \infty$ (i.e., if

\footnotetext{
${ }^{12}$ Welfare $W(\zeta)$ is equal to the value function of households (see Proposition 2); we emphasize its dependance on the the capital requirement $\zeta$ chosen at $t=0$ by the regulator.
} 


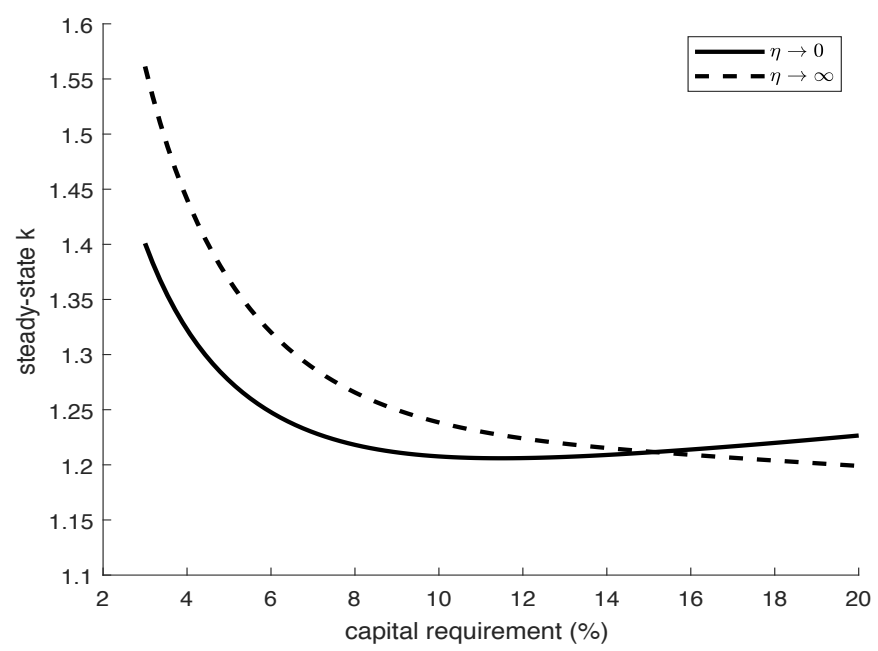

Figure 3. Both lines in the figure plot the steady-state level of physical capital $k$ for values of the capital requirement $\zeta$ ranging from $3 \%$ to $20 \%$. Parameter values are $\beta=0.95, p_{z}=0.95, \delta=0.1, A=0.52, \sigma=0.063, \chi=0.96$, and $\gamma=0.3$. We choose $A, \sigma$, and $\chi$ to induce a deposit premium of $2 \%$, a default probability of $10 \%$, and an equilibrium consumption value of 1 . The dotted line assumes a fully-elastic labor supply (i.e. $\eta \rightarrow \infty$ ); the solid line assumes a fixed labor supply (i.e. $\eta \rightarrow 0$ ), where labor supply is fixed at $\bar{l}=0.555$. Details on these calculations are in Appendix C.

labor demand is fully elastic), only the leverage effect operates; in this case, wages do not respond to changes in capital requirements, and neither do the private benefits of holding deposits.

We summarize these points in the following proposition.

Proposition 5. (Capital requirements and bad risk-taking) If $\eta<\infty$, increasing the capital requirement $\zeta$ produces two effects:

- Leverage effect. Fixing $R^{d}$, banks' debt-to-equity ratio $d / n$ decreases and banks' lending rate $r$ increases; this effect reduces the equilibrium value of physical capital $k$ and thus reduces the size of the banking sector;

- Funding effect. The deposit rate $R^{d}$ decreases; this puts downward pressure on the banks' lending rate $r$, generating an increase in the equilibrium value of physical capital $k$ and thus increasing the size of the banking sector.

If instead $\eta=\infty$, only the leverage effect operates.

An implication of Proposition 5 is that the effect of increasing capital requirements on total bank lending $k$ is ambiguous if $\eta<\infty$. If instead $\eta \rightarrow \infty$, bank lending $k$ unambiguously 
decrease. Figure 3 illustrates these results with a numerical example. The figure plots the steady-state value of bank assets $k$ for various values of capital requirement $\zeta$ and for the two extreme cases of $\eta \rightarrow \infty$ and $\eta \rightarrow 0$.

When $\eta \rightarrow \infty$ (i.e., dotted line in Figure 3), higher capital requirements always reduce $k$ because only the leverage effect is at work. When $\eta \rightarrow 0$ (i.e., solid line), both the leverage and funding effect are at work. In this case, lending by banks (i.e., capital $k$ ) decreases for levels of capital requirement up to $11.4 \%$. However, as the capital requirement is increased above $11.4 \%$, banks' lending $k$ goes up. This is because the leverage effect dominates for values of $\zeta$ below 11.4\%, whereas the funding effect dominates as $\zeta$ is pushed above $11.4 \%$.

The existence of the leverage effect explains why the optimal capital requirement is not too high even when the marginal social value of deposits is zero. In such a case, the objective of capital requirement is solely that of offsetting the negative effects of subsidized deposits insurance, with no consideration for the effects on deposits. In particular, in this simple model, deposit insurance gives rise to an incentive for banks to lend too much. In the numerical example in Figure 3, the best way to offset deposit insurance is to target the minimum level of $k$ that can be achieved, corresponding to a $11.4 \%$ capital requirement. However, the optimal capital requirement (computed in Figure 2) is $8.7 \%$ because it accounts for the transition from the old to the new steady state.

When mapping the theory to the data, Begenau (2018) notes that the return on deposits $R^{d}$ responds to changes in the quantity of deposits. In both her and our model, this feature gives rise to the funding effect, which runs counter to the conventional intuition that tighter capital requirements reduce bank lending. Crucially, in our model, the existence of a funding effect is associated with a Frisch elasticity of labor supply $\eta<\infty$, which in turn produces a wedge between marginal and private value of deposits as shown in Proposition 4. This wedge leads to higher optimal capital requirements than are found in models with deposits in the utility function, as we describe in the next section.

\subsection{Capital requirements and welfare}

A regulator who mistakenly uses the private value of deposits for welfare calculation, rather than the social value, will choose a capital requirement which is too low in comparison to the optimal one. This section formalizes this result. A possible reason why the regulator might incorrectly use the private value of deposits is, for instance, if the regulator in our model economy uses a model with deposits in the utility function rather than a model that accounts for the general equilibrium response of firms' input prices.

To characterize the welfare function used by a regulator that mistakenly uses the private 
value of deposits rather than the social value, consider the following experiment. Assume that the economy is an a steady state with a capital requirement $\zeta_{-1}$, and the regulator changes it to some different $\zeta$ at $t=0$. We have the following result.

Proposition 6. Assume the capital requirement is initially at $\zeta_{-1}$ and is then changed to $\zeta$ at $t=0$. The welfare function used by regulator that mistakenly uses the private value of deposits rather than the social value is

$$
W^{\text {wrong }}(\zeta)=W(\zeta)+\int_{\zeta_{-1}}^{\zeta}\left[\sum_{t=0}^{\infty} \beta^{t+1}\left(\bar{z}-w_{t}\right)\left(\left.\frac{\partial l_{t}}{\partial \zeta}\right|_{w_{t} \text { fixed }}-\frac{\partial l_{t}}{\partial \zeta}\right)\right] d \zeta
$$

where $W(\zeta)$ is the correct welfare function.

The incorrect welfare function $W^{\text {wrong }}(\zeta)$ measures welfare by including the private value of deposits in excess of the social value. The term

$$
\sum_{t=0}^{\infty} \beta^{t+1}\left(\bar{z}-w_{t}\right)\left(\left.\frac{\partial l_{t}}{\partial \zeta}\right|_{w_{t} \text { fixed }}-\frac{\partial l_{t}}{\partial \zeta}\right)
$$

denotes the private value of deposits that arises from marginally increasing the capital requirement, in excess of the social value. The private value does not account for the fact that the wage adjusts in general equilibrium and, thus, it consider a change in labor $\partial l_{t} / \partial \zeta$ calculated by fixing the wage $w_{t}$. In contrast, the social value accounts for the fact that $w_{t}$ adjusts when computing $\partial l_{t} / \partial \zeta$. To compute the "wrong" component of the welfare function (i.e., the second term on the right-hand side of equation 25), Proposition 6 integrates (26) with respect to $\zeta$, that is, it "sums over" marginal values.

The capital requirements that is truly optimal and the one chosen by the regulator that uses the private value of deposits maximize the welfare functions $W(\zeta)$ and $W^{\text {wrong }}(\zeta)$, respectively. Thus, the following corollary follows.

Corollary. The optimal capital requirement $\zeta^{*}$ solves

$$
\frac{\partial W\left(\zeta^{*}\right)}{\partial \zeta}=0
$$

whereas the capital requirement $\hat{\zeta}$ chosen by a regulator that mistakenly uses the private rather than the social value of deposits to compute welfare solve

$$
\left[\frac{\partial W(\zeta)}{\partial \zeta}+\sum_{t=0}^{\infty} \beta^{t+1}\left(\bar{z}-w_{t}\right)\left(\left.\frac{\partial l_{t}}{\partial \zeta}\right|_{w_{t} \text { fixed }}-\frac{\partial l_{t}}{\partial \zeta}\right)\right]_{\zeta=\hat{\zeta}}=0
$$




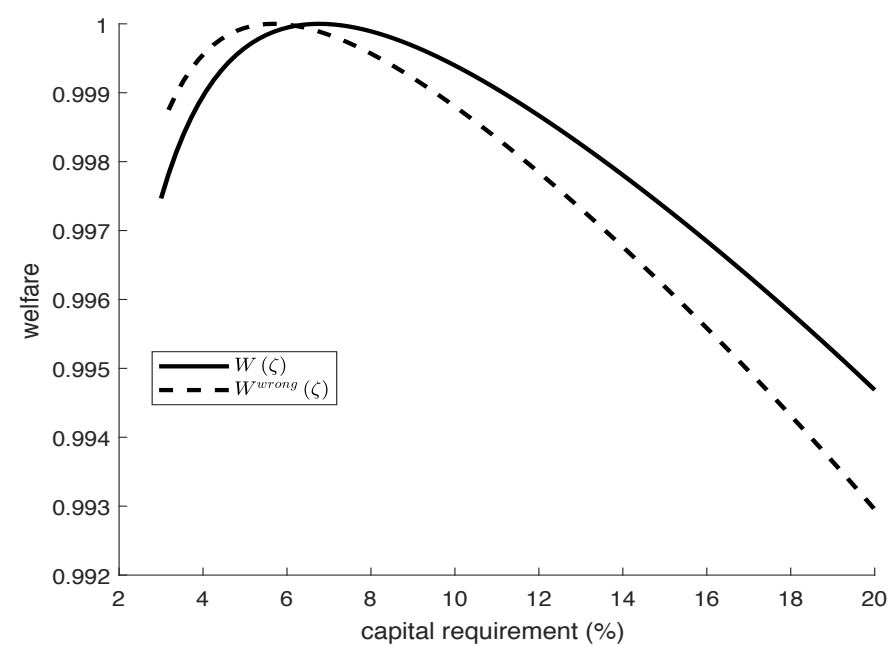

Figure 4. The solid line plots total welfare $W(\zeta)$ for values of the capital requirement $\zeta$ ranging from $3 \%$ to $20 \%$, starting from an initial steady-state where $\zeta=8 \%$. The dotted line plots the welfare $W^{\text {wrong }}(\zeta)$ that would be perceived by a regulator that mistakenly uses the private rather than the social value of deposits to compute welfare. Parameter values are $\beta=0.95, p_{z}=0.95, \delta=0.1$, $A=0.52, \sigma=0.063, \chi=0.96, \gamma=0.3$, and $\eta=1$. We choose $A, \sigma$, and $\chi$ to induce a deposit premium of $2 \%$, a default probability of $10 \%$, and an equilibrium consumption value of 1 .

If $\eta<\infty$, then $\hat{\zeta}<\zeta^{*}$.

The optimal capital requirement $\zeta^{*}$ is computed by maximizing welfare (i.e., setting the first-order condition of $W(\zeta)$ to zero, as in equation (27)). On the other hand, were a planner to mistakenly use the private rather than the social value of deposits to set the optimal capital requirement, that capital requirement $\hat{\zeta}$ would instead satisfy equation (28). This would occur, for example, if a social planner in our economy, using a model with deposits in the utility function, inferred the marginal value of deposits using the deposit premium. The above corollary shows that such a mistaken planner will always set the capital requirement too low, except in the case where $\eta \rightarrow \infty$ (i.e., except in the case in which wages are fixed in equilibrium).

Figure 4 illustrates the result of this section for an economy with a Frisch elasticity of labor supply $\eta=1 .{ }^{13}$ The solid line in Figure 4 plots the correct welfare $W(\zeta)$. The optimal capital requirement in this economy is $\zeta^{*}=6.8 \%$; we normalize $W(\zeta)$ to one at such a value. ${ }^{14}$ The dotted line in Figure 4 plots the welfare computed by a regulator who

\footnotetext{
${ }^{13}$ This is in line with standard values employed in macro-labor models and, for our purposes, is the most conservative value that is in line with the empirical evidence of Chetty et al. (2011).

${ }^{14}$ In this simple model, welfare is measured in units of consumption because of the linearity of the utility function in $c_{t}$.
} 
mistakenly uses the private rather than the social value of deposits, denoted by $W^{\text {wrong }}(\zeta)$. Details on the computation of $W(\zeta)$ and $W^{\text {wrong }}(\zeta)$ are in Appendix C.2.

The wrong welfare $W^{\text {wrong }}(\zeta)$ peaks at $\hat{\zeta}=5.5 \%$, which is a somewhat lower value than the correct optimal capital requirement $\zeta^{*}=6.8 \%$. That is, this regulator overestimates the social value of deposits and thus would set the capital requirement to a level that is lower than the truly optimal one. However, in this model both the mistaken and the correct regulator ascribe roughly the same welfare losses to setting capital requirements much too high, for example greater than $12 \%$. The quantitative, calibrated model of Section 5 will not only deliver a larger spread between the correct and incorrect optimal values of $\zeta$, but it will also magnify the extent to which the mistaken regulator overestimates the costs of setting capital requirements much higher than the optimum.

\section{Quantitative model}

In this section, we extend the model with the objective of performing a quantitative analysis. We measure the importance of the wedge between the private and social value of deposits and its impact on the optimal capital requirement regulation. The main takeaway is that considerations about the value of deposits are not first-order in setting the capital requirements, similar to the baseline model with fixed labor supply.

We extend the baseline model along four dimensions: (i) we endogenize firms' dividend policy, rather than setting it exogenously; (ii) we introduce aggregate risk; (iii) we give banks access to a technology that increases their idiosyncratic risk, subject to a cost; and (iv) we allow households to have a constant relative risk aversion (CRRA) utility from consumption, rathen than linear utility. We briefly describe these features, and then present the calibration and results.

\subsection{Extended model}

Firms' dividend policy. We endogenize firms' dividend policy by allowing firms' shareholders (i.e., households) to choose optimally the amount of dividends to be paid every period, thereby relaxing (19). The fraction of firms' wealth paid out as dividends is now possibly time-varying and firm-specifics and thus denoted by $\alpha_{t}^{i}$, rather than $\alpha$.

The optimal $\alpha_{t}^{i}$ is chosen so that the stream of dividends maximizes the value of the firm from the households' point of view (i.e., using the household discount factor). ${ }^{15}$ The next proposition shows that the dividend policy implies the same $\alpha_{t}^{i}$ at all firms, and thus

\footnotetext{
${ }^{15}$ The value of $\alpha_{t}^{i}$ can still be understood as part of the contract between shareholders and the manager.
} 
$\alpha_{t}^{i}=\alpha_{t}$ for all $i$. This follows from the simple structure of our model, which allows an easy aggregation across firms. The proposition also describes the equilibrium condition that pins down $\alpha_{t}$. The inability of the manager to differentiate away firms' idiosyncratic risk is unchanged, and so is the first-order condition (17).

Proposition 7. The optimal dividend policy from the point of view of households implies that $\alpha_{t}^{i}=\alpha_{t}$ for all $i$, and $\alpha_{t}$ is chosen so that

$$
1=E_{t}\left\{\beta\left(\frac{c_{t+1}}{c_{t}}\right)^{-\gamma_{c}}\left[\left(\bar{z}-w_{t}\right) \phi_{t}+R_{t}^{d}\right]\right\} .
$$

The choice of $\alpha_{t}$ can depend on aggregate shocks or changes in capital requirements realized at time $t$. This implies that deposits $d_{t}$ can vary in response to aggregate shocks or changes in capital requirements. This is in contrast to the baseline model, in which (19) implied that deposits $d_{t}$ were essentially pre-determined at $t-1$. In addition, note that equation (29) evaluated in the nonstochastic steady state is identical to the corresponding steady-state equation of the baseline model of Section 3, equation (20).

Because $\alpha_{t}$ is in general time-varying, the law of motion for deposits (20) is replaced by

$$
d_{t+1}=\left(1-\alpha_{t+1}\right)\left[\left(\bar{z}-w_{t}\right) \phi_{t}+R_{t}^{d}\right] d_{t}
$$

Aggregate risk and banks' risk choice. We introduce aggregate risk by assuming that the productivity of the bank-financed sector, now denoted by $A_{t+1}$, follows an $\mathrm{AR}(1)$ process in logs. The law of motion of $A_{t+1}$ is

$$
\log A_{t+1}=(1-\rho) \log \bar{A}+\rho \log A_{t}+\sigma_{A} \varepsilon_{t+1}^{A}
$$

where $\bar{A}, \sigma_{A}>0$ and $\varepsilon_{t+1}^{A} \sim \mathbb{N}(0,1)$. We replace $A$ in equations (11) and (12) with $A_{t+1}$.

We allow banks to increase their idiosyncratic volatility by paying a convex cost, similar to Van den Heuvel (2008) and Begenau (2018). Limited liability and the deposit insurance intervention together imply that bankers will avail themselves of this technology, although it is socially suboptimal. Specifically, we assume that banks can choose a probability $p_{t} \geq 0$ such that their idiosyncratic shock is $\varepsilon=0$ with probability $p_{t}$ and $\varepsilon /\left(1-p_{t}\right)$ with probability $1-p_{t}$, where $\varepsilon$ is drawn from the same distribution $F(\varepsilon)$ as in the baseline model. Without a convex cost of choosing $p_{t}$, bankers would let $p_{t}$ get arbitrarily close to 1 ; we assume that bankers pay a cost $\lambda\left(p_{t}\right) d_{t}$, where $\lambda(\cdot)$ is an increasing and convex function, specified 
below. ${ }^{16}$ The banker's problem becomes

$$
\max _{k_{t}, d_{t}, p_{t}}\left(1-p_{t}\right) E_{t} \int\left\{\frac{\varepsilon}{1-p_{t}} k_{t}\left(1-\delta+r_{t+1}\right)-R_{t}^{d} d_{t}-\lambda\left(p_{t}\right) d_{t}\right\}^{+} d F(\varepsilon)
$$

subject to $p_{t} \geq 0$ and to the same budget and capital requirement constraints as before, (7) and (8). For failed banks, the cost $\lambda\left(p_{t}\right) d_{t}$ reduces the value of assets seized by the government to partially defray the expenses of paying back depositors and, thus, increases the taxes that must be collected to fund deposit insurance. Formally, we include $\lambda\left(p_{t}\right) d_{t}$ on the right-hand side of equation (16). ${ }^{17}$

The endogenous risk chosen by banks affects welfare and the optimal regulation through two channels. First, the cost $\lambda\left(p_{t}\right) d_{t}$ reduces total output and ultimately households' consumption. Second, the ability to choose $p_{t}>0$ increases the private value of physical capital $k_{t}$ to banks, and therefore exacerbates their over-investment problem in equilibrium. Both channels increase the social value of increasing capital requirements, and higher capital requirements will lead banks to choose a lower value of $p_{t}$.

We parameterize the cost of increasing $p_{t}$ above zero using the function

$$
\lambda(p)=\lambda p \frac{1}{(1-p)^{1+\nu}}
$$

where $\lambda$ and $\nu$ are parameters. This cost function has two advantages over a more traditional one, such as a quadratic function. First, because banks will default in equilibrium, what matters to them is their expected cost, which is proportional to $\left(1-p_{t}\right) \lambda\left(p_{t}\right)$, using (30). If $\lambda\left(p_{t}\right)$ were lacking a $\left(1-p_{t}\right)^{-1}$ term, the expected marginal cost of increasing $p_{t}$ would be non-monotone and total expected cost would vanish as $p_{t} \rightarrow 1$. In contrast, the formulation in (31) guarantees that the expected marginal cost of increasing $p_{t}$ is monotone and goes to infinity as $p_{t} \rightarrow 1$. Thus, (31) ensures that we avoid multiple equilibria or implausibly high choices of $p_{t}$. Second, as we describe below, equation (31) will imply that banks optimally set $p_{t}=0$ in many states of the world, allowing for rich, non-linear dynamics. As a result, bank default will be highly non-linear, replicating the large variations observed in the data between normal times and crises. We will return to the mechanics of banks' choice of $p_{t}$ when we describe the calibration of the parameters $\lambda$ and $\nu$.

\footnotetext{
${ }^{16}$ Allowing the cost to be proportional to assets $k_{t}$, rather than deposits $d_{t}$, generates unrealistically large welfare losses of reducing capital requirements.

${ }^{17}$ The cost $\lambda\left(p_{t}\right) d_{t}$ can be interpreted as an obligation undertaken by the bank at time $t$, such as the cost to manage loans to riskier borrowers, and that must be paid to recover the value of the loans $\varepsilon k_{t}\left(1-\delta+r_{t+1}\right)$.
} 
Households' utility. Finally, we allow households to have a constant relative risk aversion (CRRA) utility function. Thus, the value function of households becomes

$$
V_{t}^{h}\left(a_{t}\right)=\max _{c_{t}, l_{t}, n_{t}} \frac{c_{t}^{1-\gamma_{c}}-1}{1-\gamma_{c}}-\beta \chi \frac{l_{t}^{1+\frac{1}{\eta}}}{1+\frac{1}{\eta}}+\beta E_{t}\left\{V_{t+1}^{h}\left(a_{t+1}\right)\right\}
$$

subject to the same budget constraint and law of motion of wealth, (14) and (15). The parameter $\gamma_{c}$ is the household's coefficient of relative risk aversion.

\subsection{Calibration and simulation}

We calibrate the model under a $8 \%$ capital requirement, and then study the welfare effect of changing such a requirement. We divide the parameters in two groups. The first set of parameters, reported in Panel A of Table 1, are set to values in line consistent with the related literature. The second set, reported in Panel B, are calibrated toward relevant data moment.

Panel A of Table 1 reports the fixed parameters for which we do not have a calibration target. We set the Frisch elasticity of labor supply $\eta$ to 1 , in line with standard approach in the macro-labro literature; this is also the most conservative value in line with Chetty et al. (2011). The discount factor $\beta=0.95$ is in line with standard calibrations, assuming that each period is one year. Standard values are also used for the depreciation of capital $(\delta=0.1)$, the Cobb-Douglas coefficient of capital $(\gamma=0.3)$, households' risk aversion $\left(\gamma_{c}=1\right.$, that is, $\log$ utility), and the autocorrelation of productivity shocks $(\rho=0.95)$. We normalize $\chi=1$ and note that changing $\chi$ has very similar effects to changing $\bar{A}$ as described below; in fact, in the illustrative model with $\eta \rightarrow \infty$, only one moment can be targeted by changing $\bar{A}$ or $\chi$. The quantitative model inherits this feature, despite the extensions and the slightly different calibration.

Panel B of Table 1 reports parameters that we calibrate towards the indicated data moments. Because the model is non-linear and we solve it globally, we do not exactly match all moments. In addition, each parameter affects all moments, but Panel B of Table 1 indicates target moments that are particularly affected by each parameter.

The average bank productivity $\bar{A}$, the standard deviation of productivity shocks, $\sigma_{A}$, and the probability of a good idiosyncratic shock to firms, $p_{z}$, are easily calibrated to match their targets. We set $\bar{A}$ to match a deposit premium of $1.87 \%$, which is the midpoint of the $3.16 \%$ deposit premium measured by Van den Heuvel (2008) and the $0.57 \%$ deposit

premium of Davydiuk (2017). Increasing $\bar{A}$ increases banks' demand for deposits, which increases $R_{t}^{d}$ and reduces the deposit premium. Targeting a higher premium would reduce 


\begin{tabular}{cccccc}
\hline \multicolumn{5}{c}{ Panel A: Set Parameters } \\
\hline Parameter & Value & Parameter & Value & Parameter & Value \\
\hline$\eta$ & 1 & $\gamma$ & 0.3 & $\chi$ & 1 \\
$\beta$ & 0.95 & $\gamma_{c}$ & 1 & & \\
$\delta$ & 0.1 & $\rho$ & 0.95 & & \\
\hline
\end{tabular}

\begin{tabular}{cclcc}
\hline \multicolumn{5}{c}{ Panel B: Calibrated Parameters } \\
\hline Parameter & Value & Target & Value (data) & Value (model) \\
\hline $\bar{A}$ & 0.68 & Deposit Premium $R^{f}-R^{d}$ & $1.87 \%$ & $1.8 \%$ \\
$\sigma_{A}$ & 0.0095 & Volatility log GDP & $1.8 \%$ & $1.8 \%$ \\
$p_{z}$ & 0.942 & Continuers Employment Growth & $2.5 \%$ & $2.5 \%$ \\
$\sigma$ & 0.027 & Avg Bank Default Probability & $0.76 \%$ & $0.77 \%$ \\
$\nu$ & 0.045 & Std Dev Bank Default Probability & $1.05 \%$ & $1.04 \%$ \\
$\lambda$ & 1.0339 & $p 90$ Bank Default Probability & $2.26 \%$ & $2.34 \%$ \\
\hline
\end{tabular}

Table 1. Calibrated Parameter Values

the optimal capital requirement; this is because a higher premium corresponds to a higher value of deposits, so that further reducing them with higher capital requirements becomes more costly. Nonetheless, a higher deposit premium (such as the $3.16 \%$ measured by Van den Heuvel, 2008) would reduce not only the optimal capital requirement but also the one chosen by a regulator that mistakenly uses the private value of deposits to infer welfare. Therefore, the quantitative importance of our novel channel would not be affected.

We set $\sigma_{A}$ to match the volatility of GDP and $p_{z}$ to match the average employment growth rate of firms that expand their labor force, corresponding to firms that receive the high value of $z_{t+1}^{i}$ in the model. This average employment growth rate is defined as

$$
g_{t+1}^{i} \equiv \frac{\widehat{l}_{t+1}^{i}-l_{t}^{i}}{\frac{1}{2}\left(\widehat{l}_{t+1}^{i}+l_{t}^{i}\right)}
$$

where $l_{t}^{i}=\phi_{t} d_{t}^{i}($ as in Proposition 1) and

$$
\begin{aligned}
\widehat{l}_{t+1}^{i} & =\left.\phi_{t+1} d_{t+1}^{i}\right|_{z_{t+1}^{i}>0} \\
& =\phi_{t+1}\left(1-\alpha_{t+1}\right)\left[\left(\frac{1}{p_{z}}-w_{t}\right) \phi_{t}+R_{t}^{d}\right] d_{t}^{i}
\end{aligned}
$$

Haltiwanger, Jarmin and Miranda (2013) show that for all but the youngest firms this growth 
rate is around $2.5 \%$.

We calibrate $\sigma, \nu$, and $\lambda$ to match three moments of the time-series variation in the default probability of banks. We measure bank default probabilities using the FDIC's Historical Statistics on Banking from 1975 to 2016. We define the default probability of banks as the number of bank failures in a given year reported by the FDIC, divided by the total number of banks covered by the FDIC. This yields an average default probability of $0.76 \%$, as in Davydiuk (2017), which is mostly affected by $\sigma$. We also target the standard deviation and the 90th percentile of the time-series distribution of the bank default probability; these two moments are mostly affected by $\nu$ and $\lambda$, respectively.

To clarify the calibration of $\sigma, \nu$, and $\lambda$, consider the first-order condition of banks with respect to the choice of $p_{t}$. Denoting $\xi_{t}$ to be the Lagrange multiplier of the nonnegativity constraint $p_{t} \geq 0$, we have:

$$
R_{t}^{d}+\xi_{t}=\lambda \frac{1+(\nu-1) p_{t}}{\left(1-p_{t}\right)^{1+\nu}} .
$$

At $p_{t}=0$ and $\xi_{t}=0$, the marginal cost of increasing $p_{t}$ is $\lambda$. Thus, $\lambda$ represents the lowest level of $R_{t}^{d}$ at which banks choose to increase $p_{t}$ above zero. We can thus calibrate $\lambda$ so that, most of the time, $R_{t}^{d}<\lambda$ and thus banks choose $p_{t}=0$, allowing the model to replicate low default probabilities in normal times. In particular, our choice of $\lambda$ implies that $54 \%$ of the time, banks choose $p_{t}=0 .{ }^{18}$ Once $p_{t}>0$, its elasticity with respect to $R_{t}^{d}$ is then determined by the parameter $\nu .{ }^{19}$ By varying $\sigma, \lambda$, and $\nu$ jointly we are able to match the average, standard deviation, and 90th percentile of bank default probability that we observe in the data.

The solid line in Figure 5 reports welfare in consumption-equivalent percent units for capital requirements ranging from $7 \%$ to $30 \%$, assuming that the economy begins with an $8 \%$ capital requirement. The optimal capital requirement in this economy is $18.5 \%$. This is much higher than the optimal fixed capital requirement of $5 \%$ found by Davydiuk (2017) and the $12 \%$ optimal capital requirement computed by Begenau (2018), somewhat higher than the $17 \%$ of Begenau and Landvoigt (2017), and about equal to the $18 \%$ required to eliminate runs in Egan, Hortaçsu and Matvos (2017). ${ }^{20}$

The dotted line in Figure 5 plots the welfare perceived by a regulator who uses the private value of deposits to infer welfare, which is constructed similar to $W^{\text {wrong }}(\zeta)$ defined in Proposition 6 (see Appendix C.3 for more details). The capital requirement chosen by the

\footnotetext{
${ }^{18}$ The fact that $p_{t}$ is often 0 is what allows the parameter $\sigma$ to primarily affect the average default probability, though of course $\sigma, \lambda$, and $\nu$ all jointly affect this moment.

${ }^{19}$ In particular, the elasticity is negatively related to $\nu$, so that a lower value of $\nu$ raises $p_{t}$, given $R_{t}^{d}$.

${ }^{20}$ Although Egan, Hortaçsu and Matvos (2017) find that the optimal capital requirement is 39\%, they prefer to focus on the $18 \%$ requirement that eliminates major welfare losses due to runs.
} 


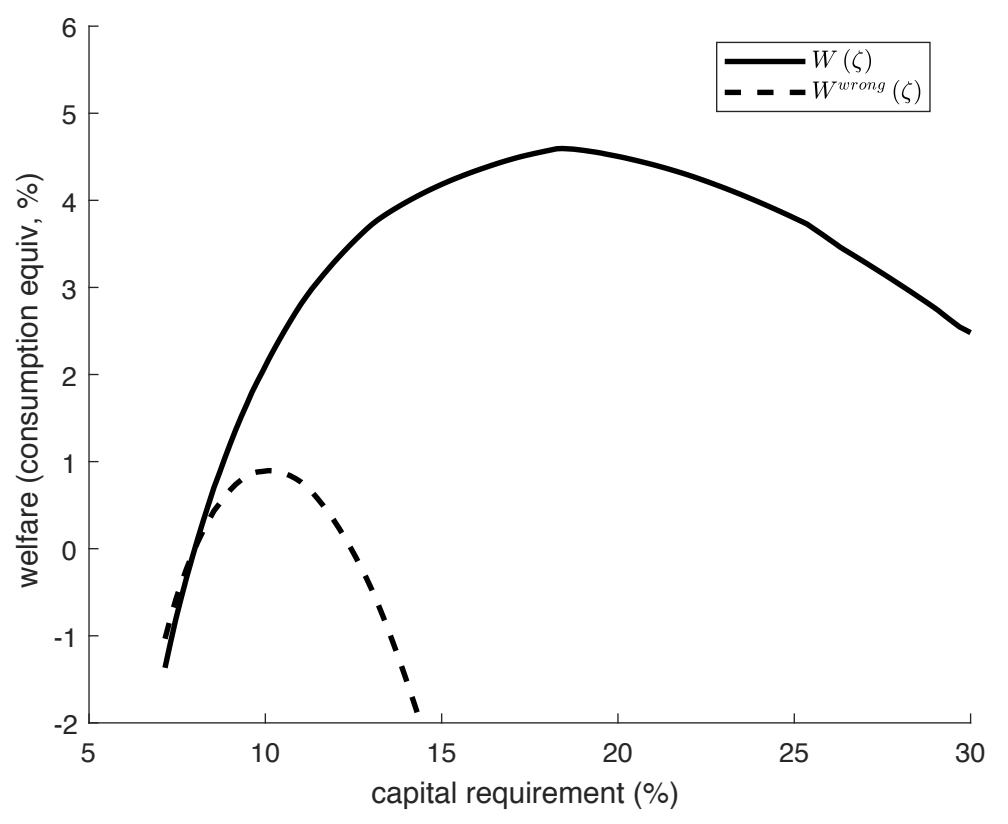

Figure 5. The solid line plots total welfare $W(\zeta)$ for values of the capital requirement $\zeta$ ranging from $7 \%$ to $30 \%$, starting from an initial steady-state where $\zeta=8 \%$. The dotted line plots the welfare $W^{\text {wrong }}(\zeta)$ that would be perceived by a regulator that mistakenly uses the private rather than the social value of deposits to compute welfare. Parameter values are in Table 1 . Welfare is defined in consumption equivalent units; that is, the percentage decrease in consumption one would have to give households in order to make them indifferent between staying in the $\zeta=8 \%$ economy, and transitioning to the economy with $\zeta$ indicated on the x-axis. We compute welfare by averaging across 1,000 simulated economies for 900 periods each, discarding the first 200 time periods and making the capital requirement change at $t=400$, which is when we begin calculating welfare. 
mistaken regulator is $10.2 \%$, higher than the $8 \%$ minimum under Basel III but lower than the Basel III "fully-phased in" level of 14\%-15\% (Basel Committee on Banking Supervision, 2017).

We also emphasize that the mistaken regulator that uses the private value of deposits perceives much larger welfare losses of setting capital requirements too high - in this case, above $12 \%{ }^{21}$ This result arises because the mistaken regulator does not realize that as capital requirements increase, input prices (in our model, the wage) will decrease, partially offsetting the costs of tighter capital requirements. Thus the elasticities of input prices with respect to $\zeta$ are key parameters for inferring the real costs of raising capital requirements.

We end with a note on the importance of accounting for dynamics and general equilibrium when analyzing optimal capital requirement regulation. A substantial fraction of the welfare losses from setting capital requirements above the optimal level of $18.5 \%$ are due to the cost of transitioning to the new steady-state. The optimal capital requirement ignoring these dynamic considerations - i.e., averaging period utility and disutility of labor over the ergodic distribution for each $\zeta$-is well over $50 \%$. The difference is due to the fact that higher capital requirements at $t$ are met on impact in part with an investment in physical capital $k_{t}$, which comes out of household consumption $c_{t}$. Variation in consumption reduces welfare because households have a finite intertemporal elasticity of substitution. However, the corresponding capital requirement that maximizes the wrong welfare $W^{\text {wrong }}(\zeta)$ that ignores both dynamics and our novel general equilibrium effect is $10.6 \%$. Thus the wedge between private and social optimality is even larger when comparing across steady-states.

\section{Conclusion}

We propose a new channel which generates an endogenous liquidity premium on safe and liquid deposits held by firms subject to idiosyncratic productivity risk. Our microfoundation of the deposit premium gives rise to a wedge between the marginal private and social values of deposits, with important implications for optimal capital regulation. In contrast to other general equilibrium models of optimal capital requirements, the deposit premium by itself is not a sufficient statistic for the welfare costs of tightening capital requirements, but instead reflects the private marginal value of deposits. Regulators using this private value will set capital requirements lower than the true optimum, which is determined by the social value.

This paper opens up several directions for future research. First, depending on how

\footnotetext{
${ }^{21} \mathrm{In}$ fact, the difference is so extreme that were we to extend the $y$-axis of Figure 5 in order to show the certainty-equivalent welfare perceived by the mistaken regulator for capital requirements greater than $15 \%$, the variation in true welfare (the solid line) would be impossible to see.
} 
firms' idiosyncratic productivities evolve over time, the value of deposits might be timevarying. This effect might give rise to important implications for the analysis of timevarying regulation above and beyond those analyzed by Davydiuk (2017) and Malherbe (2017), in which the value of deposits is constant over time and time variation in optimal capital requirements comes from time variation in banks' over-investment. Second, we have followed the literature in assuming complete deposit insurance, but Egan, Hortaçsu and Matvos (2017) show that only about half of all deposits in the US are in fact FDIC insured. Our model can be employed to study the optimal degree of deposit insurance. In our model, eliminating deposit insurance altogether increases firms' cash-flow volatility, and thus the optimal outcome is likely to be at least partial deposit insurance. This is another important novelty of our model - the literature that studies financial regulation quantitatively uses models in which zero deposit insurance would be optimal. While studying the optimal degree of deposit insurance in those models might require complicated analyses, it can be done in a relatively simple way using our framework.

\section{References}

Admati, A., and M. Hellwig. 2013. The Bankers' New Clothes: What's Wrong with Banking and What to Do about It. Princeton University Press. 2, 3

Allen, Franklin, Elena Carletti, Itay Goldstein, and Agnese Leonello. 2018. "Government Guarantees And Financial Stability." Journal of Economic Theory, 177: 518-557. 6

Arellano, Cristina, Yan Bai, and Patrick Kehoe. 2011. "Financial Markets And Fluctuations In Uncertainty." Society for Economic Dynamics 2011 Meeting Papers 896. 6

Bacchetta, Philippe, Kenza Benhima, and Céline Poilly. forthcoming. "Corporate Cash and Employment." American Economic Journal: Macroeconomics. 7

Bahaj, Saleem, and Frederic Malherbe. 2018. "The Forced Safety Effect: How Higher Capital Requirements Can Increase Bank Lending." Working Paper. 3

Bahaj, Saleem, Jonathan Bridges, Frederic Malherbe, and Cian O'Neill. 2016. "What Determines How Banks Respond To Changes In Capital Requirements?" Working Paper. 3

Basel Committee on Banking Supervision. 2017. "Basel III Monitoring Report." Report. 34 
Bates, Thomas W., Kathleen M. Kahle, and René M. Stulz. 2009. "Why Do U.S. Firms Hold So Much More Cash Than They Used To?" Journal of Finance, 64(5): 19852021. 3,7

Begenau, Juliane. 2018. "Capital Requirements, Risk Choice, and Liquidity Provision in a Business Cycle Model." Working Paper. 2, 3, 6, 11, 22, 24, 28, 32

Begenau, Juliane, and Tim Landvoigt. 2017. "Financial Regulation in a Quantitative Model of the Modern Banking System." Working paper. 3, 6, 32

Berger, Allen N., and Christa H.S. Bouwman. 2013. "How Does Capital Affect Bank Performance During Financial Crises?" Journal of Financial Economics, 109(1): 146-176. 5

Bigio, Saki. 2010. "Learning Under Fear Of Floating." Journal of Economic Dynamics and Control, 34(10): 1923-1950. 7

Chetty, Raj, Adam Guren, Day Manoli, and Andrea Weber. 2011. "Are Micro And Macro Labor Supply Elasticities Consistent? A Review Of Evidence On The Intensive And Extensive Margins." American Economic Review, 101(3): 471-75. 26, 30

Christiano, Lawrence, and Daisuke Ikeda. 2013. "Leverage Restrictions In A Business Cycle Model." National Bureau of Economic Research Working Paper 18688. 6

Corbae, Dean, and Pablo D'Erasmo. 2014. "Capital Requirements in a Quantitative Model of Banking Industry Dynamics." Working paper. 6

Dang, Tri Vi, Gary Gorton, Bengt Holmström, and Guillermo Ordoñez. 2017. "Banks As Secret Keepers." American Economic Review, 107(4): 1005-29. 7

Davison, Lee K., and Ashley M. Carreon. 2010. "Toward A Long-Term Strategy For Deposit Insurance Fund Management." FDIC Quarterly, 4(4): 29-37. 4

Davydiuk, Tetiana. 2017. "Dynamic Bank Capital Requirements." Working paper. 2, 3, $6,30,32,35$

DeAngelo, Harry, and René M. Stulz. 2015. "Liquid-Claim Production, Risk Management, And Bank Capital Structure: Why High Leverage Is Optimal For Banks." Journal of Financial Economics, 116(2): 219-236. 2

Dempsey, Kyle. 2017. "Safer Banks, Riskier Economy? Capital Requirements with NonBank Finance." Working paper. 3, 6 
Diamond, Douglas W., and Philip H. Dybvig. 1983. "Bank Runs, Deposit Insurance, and Liquidity." The Journal of Political Economy, 91(3): 401-419. 5

Diamond, Douglas W., and Raghuram G. Rajan. 2001. "Liquidity Risk, Liquidity Creation, and Financial Fragility: A Theory of Banking." Journal of Political Economy, 109(2): 287-327. 5

Diamond, William. 2016. "Safety Transformation and the Structure of the Financial System." 7

Dindo, Pietro, Andrea Modena, and Loriana Pelizzon. 2018. "Risk Pooling, Leverage Constraints, and the Business Cycle." Working Paper. 6

Donaldson, Jason Roderick, Giorgia Piacentino, and Anjan V Thakor. forthcoming. "Household Debt and Unemployment." Journal of Finance. 7

Egan, Mark, Ali Hortaçsu, and Gregor Matvos. 2017. "Deposit Competition and Financial Fragility: Evidence from the US Banking Sector." American Economic Review, 107(1): 169-216. 6, 32, 35

Froot, Kenneth A., David S. Scharfstein, and Jeremy C. Stein. 1993. "Risk Management: Coordinating Corporate Investment And Financing Policies." The Journal of Finance, 48(5): 1629-1658. 7

Gertler, Mark, Nobuhiro Kiyotaki, and Andrea Prestipino. 2016. "Wholesale Banking And Bank Runs In Macroeconomic Modelling Of Financial Crises." National Bureau of Economic Research Working Paper 21892. 6

Glover, Brent, and Oliver Levine. 2015. "Uncertainty, Investment, And Managerial Incentives." Journal of Monetary Economics, 69: 121-137. 5, 7, 8

Glover, Brent, and Oliver Levine. 2017. "Idiosyncratic Risk And The Manager." Journal of Financial Economics, 126(2): 320-341. 5, 7,8

Gorton, Gary, and George Pennacchi. 1990. "Financial Intermediaries and Liquidity Creation." The Journal of Finance, 45(1): 49-71. 7

Gorton, Gary, Stefan Lewellen, and Andrew Metrick. 2012. "The Safe-Asset Share." American Economic Review, 102(3): 101-106. 6 
Haltiwanger, John, Ron S. Jarmin, and Javier Miranda. 2013. "Who Creates Jobs? Small Versus Large Versus Young." The Review of Economics and Statistics, 95(2): 347361. 31

Herskovic, Bernard, Bryan Kelly, Hanno Lustig, and Stijn Van Nieuwerburgh. 2016. "The Common Factor In Idiosyncratic Volatility: Quantitative Asset Pricing Implications." Journal of Financial Economics, 119(2): 249-283. 7

Jermann, Urban, and Vincenzo Quadrini. 2012. "Macroeconomic Effects Of Financial Shocks." American Economic Review, 102(1): 238-271. 7

Kashkari, Neel. 2016. "The Minneapolis Plan to End Too Big to Fail." Inaugural Address given at the Economic Club of New York, November 16, 2016. 2

Krishnamurthy, Arvind, and Annette Vissing-Jorgensen. 2012. "The Aggregate Demand For Treasury Debt." Journal of Political Economy, 120(2): 233-267. 6

Li, Yiting, Guillaume Rocheteau, and Pierre-Olivier Weill. 2012. "Liquidity And The Threat Of Fraudulent Assets." Journal of Political Economy, 120(5): 815-846. 8

Magill, Michael J.P., Martine Quinzii, and Jean-Charles Rochet. 2016. "Unconventional Monetary Policy and the Safety of the Banking System." Working Paper. 7

Malherbe, Frederic. 2017. "Optimal Capital Requirements Over The Business And Financial Cycles." Society for Economic Dynamics 2015 Meeting Papers 1154. 3, 35

Mehran, Hamid, and Anjan Thakor. 2011. "Bank Capital And Value In The CrossSection." The Review of Financial Studies, 24(4): 1019-1067. 5

Minton, Bernadette A., and Catherine Schrand. 1999. "The Impact Of Cash Flow Volatility On Discretionary Investment And The Costs Of Debt And Equity Financing." Journal of Financial Economics, 54(3): 423-460. 7

Modigliani, Franco, and Merton H. Miller. 1958. "The Cost of Capital, Corporation Finance and the Theory of Investment." The American Economic Review, 48(3): 261-297. 2,5

Nagel, Stefan. 2016. "The Liquidity Premium Of Near-Money Assets*." The Quarterly Journal of Economics, 131(4): 0-1927. 6

Nguyễn, Thiên. 2014. "Bank Capital Requirements: A Quantitative Analysis." Working paper. 3,6 
Nikolov, Boris, and Toni M. Whited. 2014. "Agency Conflicts And Cash: Estimates From A Dynamic Model." The Journal of Finance, 69(5): 1883-1921. 5, 8

Opler, Tim, Lee Pinkowitz, René Stulz, and Rohan Williamson. 1999. "The Determinants And Implications Of Corporate Cash Holdings." Journal of Financial Economics, 52(1): 3-46. 10

Panousi, Vasia, and Dimitris Papanikolaou. 2012. "Investment, Idiosyncratic Risk, And Ownership." The Journal of Finance, 67(3): 1113-1148. 5, 7, 8

Quadrini, Vincenzo. 2017. "Bank Liabilities Channel." Journal of Monetary Economics, 89(Supplement C): 25-44. Carnegie-Rochester-NYU Conference Series on the Macroeconomics of Liquidity in Capital Markets and the Corporate Sector. 3, 6, 8

Rouwenhorst, K. Geert. 1995. "Asset Pricing Implications of Real Business Cycle Models." In Frontiers of Business Cycle Research. , ed. Thomas F. Cooley, 294-330. Princeton University Press. 50

Smith, Clifford W., and René M. Stulz. 1985. "The Determinants Of Firms' Hedging Policies." The Journal of Financial and Quantitative Analysis, 20(4): 391-405. 7

Stein, Jeremy C. 2012. "Monetary Policy As Financial Stability Regulation." The Quarterly Journal of Economics, 127(1): 57-95. 7

Thakor, Anjan V. 2014. "Bank Capital And Financial Stability: An Economic Trade-Off Or A Faustian Bargain?" Annual Review of Financial Economics, 6(1): 185-223. 5

Van den Heuvel, Skander J. 2008. "The Welfare Cost Of Bank Capital Requirements." Journal of Monetary Economics, 55(2): 298-320. 2, 3, 6, 11, 28, 30, 31

Van den Heuvel, Skander J. 2018. "The Welfare Eøects of Bank Liquidity and Capital Requirements." Working paper. 7

Veronesi, Pietro, and Luigi Zingales. 2010. "Paulson's Gift." Journal of Financial Economics, 97(3): 339-368. The 2007-8 financial crisis: Lessons from corporate finance. 4 


\section{Appendix}

\section{A Proofs}

Proof of Proposition 1. We conjecture and later verify that the value function has the form

$$
V_{t}^{m}\left(d_{t}^{i}\right)=\theta \frac{\beta}{1-\beta} \log \left(d_{t}^{i}\right)+\Xi_{t}
$$

where $\Xi_{t}$ is independent of $d_{t}^{i}$. Then, the problem of the manager implies the first-order condition in (17). Since $l_{t}^{i}$ is independent of $d_{t}^{i}$, the conjecture about the value function can be verified, obtaining

$$
\Xi_{t}=\theta \frac{\beta}{1-\beta}\left\{\log (\kappa \alpha)+\frac{\beta}{1-\beta} \log (1-\alpha)+\frac{1}{1-\beta} E_{t} \log \left[\left(z_{t+1}^{i}-w_{t}\right) \phi_{t}+R_{t}^{d}\right]\right\}
$$

Proof of Proposition 2. The first-order condition in (17) does not depend on $\kappa$ and thus holds for any $\kappa>0$. Manager $i$ 's consumption converges to zero, using (3). To show that the manager's value function converges to zero, we use the specification of the value function stated in the proof of Proposition 1, equation (34); under the assumption that $\theta=\eta_{1} \kappa^{\eta_{2}}$ with $\eta_{1}, \eta_{2}>0$, we have

$$
\theta \frac{\beta}{1-\beta} \log \left(d_{t}^{i}\right) \downarrow 0
$$

and $\Xi_{t} \downarrow 0$ as $\kappa \downarrow 0$, where $\Xi_{t}$ is defined in equation (35). The result about dividends follows using equation (4).

Proof of Proposition 3. To show $R^{d}<1 / \beta$, we first establish that $w<E_{t}\left\{z_{t+1}^{i}\right\}$. First, note that $w \leq E_{t}\left\{z_{t+1}^{i}\right\}$, otherwise firms would make negative profits on average and thus will not hire any workers, and the labor market will not clear. Next, assume by contradiction that $w=E_{t}\left\{z_{t+1}^{i}\right\}$. Equation (17) and the assumption that $\operatorname{Var}\left(z_{t+1}^{i}\right)>0$ imply that $\phi=0$ and thus firms will not hire any workers, and the labor market will not clear. Thus, the only possible case if $w<E_{t}\left\{z_{t+1}^{i}\right\}$. This result and equation (20) evaluated in steady state imply $R^{d}<1 / \beta$ and $1 / \beta-R^{d}=(\bar{z}-w) \phi$. Finally, the right-hand side of (24) can be computed using $l_{t}^{i}=\phi d_{t}^{i}$ and $E_{t}\left\{z_{t+1}^{i}\right\}=\bar{z}$, establishing the result. 
To prove Propositions 4 and 5, we first state and prove the following intermediate lemma.

Lemma 8. If there exists a steady-state equilibrium with $l>0$, we have

$$
\frac{\partial d}{\partial \zeta}<0, \frac{\partial R^{d}}{\partial \zeta}<0, \frac{\partial w}{\partial \zeta}<0, \frac{\partial \phi}{\partial \zeta}>0, \frac{\partial l}{\partial \zeta}<0
$$

for all $\eta \in(0,1)$. Moreover the sign of $\partial d / \partial \zeta$ is also preserved in the limit as $\eta \rightarrow 0$ and $\eta \rightarrow \infty$, whereas $\partial R^{d} / \partial \zeta<0$ as $\eta \rightarrow 0$ but $\partial R^{d} / \partial \zeta \rightarrow 0$ as $\eta \rightarrow \infty$.

Proof of Lemma 8. We totally differentiate (17), the law of motion of deposits (2) evaluated in steady-state and integrated over $i$, the labor demand equation $l=\phi d$, and the first-order condition of banks (23). Thus, we obtain a system of four equations in four unknowns, where the unknowns are $\partial w / \partial \zeta, \partial \phi / \partial \zeta, \partial R^{d} / \partial \zeta$, and $\partial d / \partial \zeta$. To derive the results, it is useful to define the following variables

$$
\begin{aligned}
& \mathbb{A} \equiv E\left\{\frac{R^{d}}{\left[\phi\left(z^{\prime}-w\right)+R^{d}\right]^{2}}\right\}>0 \\
& \mathbb{B} \equiv E\left\{\frac{\left(z^{\prime}-w\right)^{2}}{\left[\phi\left(z^{\prime}-w\right)+R^{d}\right]^{2}}\right\}>0 \\
& \mathbb{C} \equiv E\left\{-\frac{\left(z^{\prime}-w\right)}{\left[\phi\left(z^{\prime}-w\right)+R^{d}\right]^{2}}\right\}>0 \\
& \mathbb{D} \equiv E\left\{\frac{1}{\phi\left(z^{\prime}-w\right)+R^{d}}\right\}>0 .
\end{aligned}
$$

The signs of $\mathbb{A}, \mathbb{B}$, and $\mathbb{D}$ hold because the argument of the expectation is positive for all states. The sign of $\mathbb{C}$ follows from three remarks. First, $\mathbb{C}$ is a cross-partial derivative of the manager's objective function with respect to $R^{d}$ and $\phi$, that is,

$$
\frac{\partial}{\partial R^{d}} \frac{\partial \text { (manager's objective function) }}{\partial \phi}=\mathbb{C}
$$

where

$$
\text { (manager's objective function) }=\beta^{m} E_{t}\left\{\theta \log c_{t+1}^{i}+V_{t+1}^{m}\left(d_{t+1}^{i}\right)\right\} \text {. }
$$

Second, since the objective function of the manager is concave in $\phi$ (i.e., the first-order condition with respect to $\phi$ pins down a maximum), then its derivative with respect to $\phi$ is locally decreasing in $\phi$. Third, (17) implies a constant ratio $\phi / R^{d}$, and thus a marginal increase in $R^{d}$ implies an increase in $\phi$. Thus, $\mathbb{C}$ must be positive when evaluated at equilibrium values. 
We can then solve the system of four equations in four unknowns described before. For deposits, we obtain

$$
\frac{\partial d}{\partial \zeta}=-\frac{\left(\frac{1}{\beta}-R^{d} \int_{\underline{\varepsilon}}^{\infty} d F(\varepsilon)+\frac{A(1-\gamma) \gamma \int_{\underline{\varepsilon}}^{\infty} \varepsilon d F(\varepsilon)}{\left(d^{1-\gamma}\right)(1-\zeta)^{\gamma-1}}\right)\left(d \mathbb{D}+\frac{\eta(\mathbb{B}+\mathbb{C}(\bar{z}-w))}{w^{1-\eta} \chi^{\eta}}\right)}{\frac{A(1-\gamma) \gamma \int_{\varepsilon}^{\infty} \varepsilon d F(\varepsilon)}{\left(d^{2-\gamma}\right)(1-\zeta)^{\gamma-1}}\left[d \mathbb{D}+\frac{\eta(\mathbb{B}+\mathbb{C}(\bar{z}-w))}{w^{1-\eta} \chi^{\eta}}\right]+(1-\zeta) \int_{\underline{\varepsilon}}^{\infty} d F(\varepsilon) \phi[\mathbb{A}(\bar{z}-w)+\mathbb{B} \phi]}<0,
$$

where the inequality follows from the fact that both the numerator and the denominator on the right-hand side are positive, using $R^{d}<1 / \beta$ and $w<\bar{z}$ (which must both hold otherwise firms would make negative profits) and the signs of $\mathbb{A}, \mathbb{B}, \mathbb{C}$, and $\mathbb{D}$ established before. The sign of the derivative is preserved in the limit as $\eta \rightarrow 0$ and $\eta \rightarrow \infty$, using the labor supply equation (21).

Similar, for the return on deposits, we obtain

$$
\frac{\partial R^{d}}{\partial \zeta}=-\frac{\phi(\mathbb{A}(\bar{z}-w)+\mathbb{B} \phi)\left(\frac{1}{\beta}-R^{d} \int_{\underline{\varepsilon}}^{\infty} d F(\varepsilon)+\frac{A(1-\gamma) \gamma \int_{\underline{\varepsilon}}^{\infty} \varepsilon d F(\varepsilon)}{\left(d^{1-\gamma}\right)(1-\zeta)^{\gamma-1}}\right)}{\frac{A(1-\gamma) \gamma \int_{\underline{\varepsilon}}^{\infty} \varepsilon d F(\varepsilon)}{\left(d^{2-\gamma}\right)(1-\zeta)^{\gamma-1}}\left(d \mathbb{D}+\frac{\eta(\mathbb{B}+\mathbb{C}(\bar{z}-w))}{w^{1-\eta} \chi^{\eta}}\right)+(1-\zeta) \int_{\underline{\varepsilon}}^{\infty} d F(\varepsilon) \phi[\mathbb{A}(\bar{z}-w)+\mathbb{B} \phi]}<0,
$$

and taking the limit as $\eta$ goes to zero or $\infty$ we can established the respective result.

For the wage, we obtain

$$
\frac{\partial w}{\partial \zeta}=-\frac{\phi(\mathbb{B}+\mathbb{C}(\bar{z}-w))\left(\frac{1}{\beta}-R^{d} \int_{\underline{\varepsilon}}^{\infty} d F(\varepsilon)+\frac{A(1-\gamma) \gamma \int_{\underline{\varepsilon}}^{\infty} \varepsilon d F(\varepsilon)}{\left(d^{1-\gamma}\right)(1-\zeta)^{\gamma}}\right)}{\frac{A(1-\gamma) \gamma \int_{\underline{\varepsilon}}^{\infty} \varepsilon d F(\varepsilon)}{\left(d^{2-\gamma}\right)(1-\zeta)^{\gamma-1}}\left(d \mathbb{D}+\frac{\eta(\mathbb{B}+\mathbb{C}(\bar{z}-w))}{w^{1-\eta} \chi^{\eta}}\right)+(1-\zeta) \int_{\underline{\varepsilon}}^{\infty} d F(\varepsilon) \phi[\mathbb{A}(\bar{z}-w)+\mathbb{B} \phi]}<0
$$

and for the manager's risk-taking choice $\phi$ we obtain

$$
\frac{\partial \phi}{\partial \zeta}=\frac{\phi \mathbb{D}\left(\frac{1}{\beta}-R^{d} \int_{\underline{\varepsilon}}^{\infty} d F(\varepsilon)+\frac{A(1-\gamma) \gamma \int_{\underline{\varepsilon}}^{\infty} \varepsilon d F(\varepsilon)}{\left(d^{1-\gamma}\right)(1-\zeta)^{\gamma}}\right)}{\frac{A(1-\gamma) \gamma \int_{\varepsilon}^{\infty} \varepsilon d F(\varepsilon)}{\left(d^{2-\gamma}\right)(1-\zeta)^{\gamma-1}}\left(d \mathbb{D}+\frac{\eta(\mathbb{B}+\mathbb{C}(\bar{z}-w))}{w^{1-\eta} \chi^{\eta}}\right)+(1-\zeta) \int_{\underline{\varepsilon}}^{\infty} d F(\varepsilon) \phi[\mathbb{A}(\bar{z}-w)+\mathbb{B} \phi]}>0 .
$$

Finally, using $l=\phi d$, totally differentiating with respect to $\zeta$, and using the previous results, we obtain

$$
\frac{\partial l}{\partial \zeta}=-\frac{\left(\frac{1}{\beta}-R^{d} \int_{\underline{\varepsilon}}^{\infty} d F(\varepsilon)+\frac{A(1-\gamma) \gamma \int_{\varepsilon}^{\infty} \varepsilon d F(\varepsilon)}{\left(d^{1-\gamma}\right)(1-\zeta)^{\gamma}}\right)\left[\phi \frac{\eta(\mathbb{B}+\mathbb{C}(\bar{z}-w))}{w^{1-\eta} \chi^{\eta}}\right]}{\frac{A(1-\gamma) \gamma \int_{\varepsilon}^{\infty} \varepsilon d F(\varepsilon)}{\left(d^{2-\gamma}\right)(1-\zeta)^{\gamma-1}}\left(d \mathbb{D}+\frac{\eta(\mathbb{B}+\mathbb{C}(\bar{z}-w))}{w^{1-\eta} \chi^{\eta}}\right)+(1-\zeta) \int_{\underline{\varepsilon}}^{\infty} d F(\varepsilon) \phi[\mathbb{A}(\bar{z}-w)+\mathbb{B} \phi]}<0 .
$$


Proof of Proposition 4. For $\eta \in(0, \infty)$, the results are shown in Lemma 8. For the case $\eta \rightarrow \infty$ and $\eta \rightarrow 0$, the results follow as corollaries of the proof of Lemma 8, using the labor supply (21) and taking the appropriate limits with respect to $\eta$.

Proof of Proposition 5. Combining (12), (22), and (23) evaluated at the non-stochastic steady state, we obtain:

$$
\int_{\underline{\varepsilon}}^{\infty} \varepsilon\left(1-\delta+A \gamma k^{\gamma-1}\right) d F(\varepsilon)=\zeta \frac{1}{\beta}+(1-\zeta) R^{d} \int_{\underline{\varepsilon}}^{\infty} d F(\varepsilon)
$$

Totally differentiating with respect to $\zeta$, we have:

$$
\int_{\underline{\varepsilon}}^{\infty} \varepsilon\left(A \gamma(\gamma-1) k^{\gamma-2} \frac{\partial k}{\partial \zeta}\right) d F(\varepsilon)=\left[\frac{1}{\beta}-R^{d} \int_{\underline{\varepsilon}}^{\infty} d F(\varepsilon)\right]+(1-\zeta) \frac{\partial R^{d}}{\partial \zeta} \int_{\underline{\varepsilon}}^{\infty} d F(\varepsilon)
$$

Fixing $R^{d}$, and since the term in square brackets on the right-hand side is positive (because $R^{d}<1 / \beta$ in equilibrium), then capital $k$ drops when $\zeta$ marginally increases (leverage effect).

The fundind effect follows from the fact that $R^{d}$ weakly decreases, as established in Lemma 8.

Proof of Proposition 6. The welfare function is given by

$$
\begin{aligned}
W(\zeta) & =\sum_{t=0}^{\infty} \beta^{t}\left[c_{t}-\beta \chi \frac{l_{t}^{1+1 / \eta}}{1+1 / \eta}\right] \\
& =\sum_{t=0}^{\infty} \beta^{t}\left[A k_{t-1}^{\gamma}+\bar{z} l_{t-1}-\left(k_{t}-(1-\delta) k_{t-1}\right)-\beta \chi \frac{l_{t}^{1+1 / \eta}}{1+1 / \eta}\right],
\end{aligned}
$$

where the second line replaces $c_{t}$ using Walras' law, so that consumption is equal to output $A k_{t-1}^{\gamma}$ produced by the bank-financed sector plus output $\bar{z} l_{t-1}$ produced by firms and minus investments in physical capital $k_{t}-(1-\delta) k_{t-1}$. Totally differentiantiating with respect to $\zeta$, we obtain the marginal effect on social welfare of increasing the capital requirement $\zeta$ :

$$
\begin{aligned}
W^{\prime}(\zeta) & =\sum_{t=1}^{\infty} \beta^{t}\left[\left(A \gamma k_{t-1}^{\gamma-1}-\left(\frac{1}{\beta}-1+\delta\right)\right) \frac{\partial k_{t-1}}{\partial \zeta}+\left(\bar{z}-\chi l_{t-1}^{1 / \eta}\right) \frac{\partial l_{t-1}}{\partial \zeta}\right] \\
& =\sum_{t=1}^{\infty} \beta^{t}\left[\left(A \gamma k_{t-1}^{\gamma-1}-\left(\frac{1}{\beta}-1+\delta\right)\right) \frac{\partial k_{t-1}}{\partial \zeta}+\left(\bar{z}-w_{t-1}\right) \frac{\partial l_{t-1}}{\partial \zeta}\right],
\end{aligned}
$$


where the second line uses the labor supply equation (21). Similar, the marginal effect on social welfare for a regulator that mistakenly uses the private rather than the social value of deposits is

$$
\left(W^{\text {wrong }}\right)^{\prime}(\zeta)=\sum_{t=1}^{\infty} \beta^{t}\left[\left(A \gamma k_{t-1}^{\gamma-1}-\left(\frac{1}{\beta}-1+\delta\right)\right) \frac{\partial k_{t-1}}{\partial \zeta}+\left.\left(\bar{z}-w_{t-1}\right) \frac{\partial l_{t-1}}{\partial \zeta}\right|_{w_{t-1} \text { fixed }}\right]
$$

because such a regulator takes the wage as given, similar to private agents. Thus, (36) and (37) imply

$$
\left(W^{\text {wrong }}\right)^{\prime}(\zeta)=W^{\prime}(\zeta)+\sum_{t=0}^{\infty} \beta^{t+1}\left(\bar{z}-w_{t}\right)\left(\left.\frac{\partial l_{t}}{\partial \zeta}\right|_{w_{t} \text { fixed }}-\frac{\partial l_{t}}{\partial \zeta}\right)
$$

Integrating (38) from the current capital requirement $\zeta_{-1}$ to the new capital requirement $\zeta$, the result follows.

Proof of Proposition \%. Define the value of the firm before-dividends as $V_{t}^{f}\left(x_{t}^{i}\right)$, from the point of view of shareholders. This value corresponds to the present-discounted stream of dividends, discounted using the stochastic discount factor of households, and where the choice of dividends is made optimally to maximize households' utility. Let $\alpha_{t}^{i}$ be the fraction of firm $i$ wealth paid out as dividends. Then,

$$
V_{t}^{f}\left(x_{t}^{i}\right)=\max _{\alpha_{t}^{i}} \alpha_{t}^{i} x_{t}^{i}+\beta E_{t}\left\{\left(\frac{c_{t+1}}{c_{t}}\right)^{-\gamma_{c}} V_{t+1}^{f}\left(x_{t+1}^{i}\right)\right\}
$$

where

$$
\begin{aligned}
x_{t+1}^{i} & =\left(z_{t+1}^{i}-w_{t}\right) l_{t}+R_{t}^{d} d_{t} \\
& =\left[\left(z_{t+1}^{i}-w_{t}\right) \phi_{t}+R_{t}^{d}\right] d_{t} \\
& =\left[\left(z_{t+1}^{i}-w_{t}\right) \phi_{t}+R_{t}^{d}\right]\left(1-\alpha_{t}^{i}\right) x_{t}^{i},
\end{aligned}
$$

and the last line uses $d_{t}=\left(1-\alpha_{t}^{i}\right) x_{t}^{i}$. Note that $\phi_{t}$ is taken as given because it is chosen by the manager.

The first-order condition with respect to $\alpha_{t}^{i}$ implies

$$
1=\beta E_{t}\left\{\left(\frac{c_{t+1}}{c_{t}}\right)^{-\gamma_{c}}\left[\left(z_{t+1}^{i}-w_{t}\right) \phi_{t}+R_{t}^{d}\right]\left(V_{t+1}^{f}\right)^{\prime}\left(x_{t+1}^{i}\right)\right\}
$$


where the marginal value of the firm can be computed recursively using the envelope condition

$$
\left(V_{t}^{f}\right)^{\prime}\left(x_{t}^{i}\right)=\alpha_{t}^{i}+\beta E_{t}\left\{\left(\frac{c_{t+1}}{c_{t}}\right)^{-\gamma_{c}}\left(1-\alpha_{t}^{i}\right)\left[\left(z_{t+1}^{i}-w_{t}\right) \phi_{t}+R_{t}^{d}\right]\left(V_{t+1}^{f}\right)^{\prime}\left(x_{t+1}^{i}\right)\right\} .
$$

The previous two equations imply $\left(V_{t}^{f}\right)^{\prime}\left(x_{t}^{i}\right)=1$ for all $t$, and thus (39) simplies to

$$
1=\beta E_{t}\left\{\left(\frac{c_{t+1}}{c_{t}}\right)^{-\gamma_{c}}\left[\left(z_{t+1}^{i}-w_{t}\right) \phi_{t}+R_{t}^{d}\right]\right\}
$$

We then note that $z_{t+1}^{i}$ is i.i.d. and independent of all other endogenous variables at $t+1$, and thus it can be replaced with its expectation $\bar{z}$, obtaining (29). In addition, the condition that pins down $\alpha_{t}^{i}$ is the same for all firms, and thus $\alpha_{t}^{i}=\alpha_{t}$ for all $i$.

\section{B Benchmark with no shocks: Modigliani-Miller}

In this Appendix, we characterize the equilibrium in a version of the model in which we shut down all shocks - both the idiosyncratic shocks to entrepreneurs and banks, and the aggregate productivity shock. The objective is to establish a benchmark that can be used as a comparison for the analyses that follow.

An implication of shutting down the shocks to banks is that there is de facto no deposit insurance. This is because banks' profits are fully deterministic and thus no bank fails in equilibrium, implying that deposit insurance disbursements are zero.

In this benchmark scenario, Modigliani-Miller holds in the sense that the equilibrium is independent of how banks' assets are financed. The restriction on $\alpha$ imposed in (29) is essential to obtain such a result. To overcome the indeterminacy of Modigliani-Miller, we assume that capital requirements are imposed anyway by the regulator, even though there is no deposit insurance disbursement, and that they are satisfied with equality: $n_{t} / k_{t}=\zeta$. We view this result as a "check" that our framework allows for the Modigliani-Miller theorem to hold once we shut down deposit insurance and the uninsurable idiosyncratic risk of firms.

Proposition 9. (Benchmark equilibrium without any shock) Suppose $z_{t+1}^{i} \equiv 1$, and $\varepsilon \equiv 1$. Given $\zeta$, the equilibrium is characterized by prices $R^{d}=R^{n}=1 / \beta, w=1$; banking variables $k=\left[\left(\frac{1}{\beta}-(1-\delta)\right) \frac{1}{A \gamma}\right]^{-\frac{1}{1-\gamma}}, d=k(1-\zeta)$, and $n=\zeta k ;$ labor $l=(1 / \chi)^{\eta} ;$ taxes $T=0$; and consumption of households $c=(1 / \chi)^{\eta}+A k^{\gamma}-\delta k$. 
Proof. Since there are no idiosyncratic shocks to firms, the first-order condition (17) implies $w=1$, which in turn implies the equilibrium value of labor stated in the proposition, using (21). The law of motion of deposits, (2), evaluated in steady state (i.e., at $d_{t}^{i}=d_{t+1}^{i}$ ) and using the restriciton on $\alpha$ in (19), implies $R^{d}=1 / \beta$. Given this result, and since no bank fail in equilibrium because shocks are shut down, equation (23) implies $1-\delta+r=1 / \beta$ which, together with the first-order condition of bank-finance firms, (12), implies the value of capital $k$ stated in the proposition. The value of deposits and equity follows from the bank's budget and capital-requirement constraints, (7) and (8). Taxes $T=0$ follow from the fact that no bank fails in equilibrium, and consumption follows from Walras' Law.

\section{Solution Method}

In this section we describe the numerical method for solving the numerical examples in Section 4 and the quantitative model in Section 5. We take all parameters as given and constant.

\section{C.1 Steady state of the baseline model of Section 3}

We describe how we solve for the steady-state of the baseline model of Section 3. We use this method to generate initial conditions to perform the policy experiments represented in Figures 2 and 4, and to produce Figure 3. We denote steady-state variables by dropping all time subscripts.

First, because the deposit premium is positive as shown by Proposition 3, the capital constraint always binds. Thus, equations (7) and (8) together imply that

$$
\begin{aligned}
& n=\zeta k \\
& d=(1-\zeta) k .
\end{aligned}
$$

Equation (12) can be used to solve for $k$,

$$
k=\left[\frac{\gamma A}{r}\right]^{\frac{1}{1-\gamma}}
$$

and equation (20) implies that

$$
R^{d}=\frac{1}{\beta}-(\bar{z}-w) \phi
$$


Plugging this equation into equation (17) yields

$$
0=E\left\{\frac{z^{\prime}-w}{\left(z^{\prime}-\bar{z}\right) \phi+\frac{1}{\beta}}\right\}
$$

To solve for the steady state, we guess a value for $w$. Given this value for $w$, we solve equation (44) for $\phi$, noting that $\phi \in(0,1 / \beta)$ because there is a positive probability that $z^{\prime}=0$. We then have $R^{d}$ from equation (43). We then plug (10), (22), and (41) into (23) and, using the value of $R^{d}$ just computed, we solve for $r$. In particular, since $\varepsilon$ is $\log$-normal with mean 1 , we have

$$
\begin{gathered}
\int_{\underline{\varepsilon}}^{\infty} \varepsilon d F(\varepsilon)=1-\Phi\left\{\frac{1}{\sigma} \underline{\varepsilon}-\frac{1}{2} \sigma\right\}, \\
\operatorname{Pr}\{\varepsilon \geq \underline{\varepsilon}\}=1-\Phi\left\{\frac{1}{\sigma} \underline{\varepsilon}+\frac{1}{2} \sigma\right\},
\end{gathered}
$$

where $\Phi\{\cdot\}$ denotes the standard normal CDF. Given $r$, we can find $n, d$, and $k$ from equations (40)-(42). Finally, we search over values of $w \in(0, \bar{z})$ to satisfiy equation (21), given $l=\phi d$ (from Proposition 1) computed using the implied values of $d$ and $\phi$.

\section{C.2 Changing capital requirements at $t=0$ : numerical examples of Section 4}

We now describe how we solve the model to compute the welfare plotted in Figures 2 and 4. We perform the following policy experiment. Given the economy in steady-state with an $8 \%$ capital requirement, we vary the capital to a new level, ranging from $\zeta=3 \%$ to $\zeta=20 \%$. For each new level of capital requirement in this range, we solve for the equilibrium transition path to the new steady state. We then compute welfare over this path, $W(\zeta)$, which is equal to the value function of households $V_{0}^{h}\left(a_{0}\right)$ as discussed in Section 3.3. ${ }^{22}$

Assume the economy is in steady-state up to $t=0$. At the start of $t=1$, a new capital requirement $\zeta$ is announced. ${ }^{23}$ Deposits $d_{t}$ are pre-determined at time $t-1$ from equation (20). Thus $d_{1}=d_{0}$.

We solve the model at each $t$ recursively. Suppose we know $d_{t}$. Then (7) and (8) imply $k_{t}=\frac{d_{t}}{1-\zeta_{t}}$, and $r_{t+1}$ comes directly from equation (12). We then plug equation (10) into equation (23) and solve numerically for $R_{t}^{d}$. Given $R_{t}^{d}$, we plug equation (21) into

\footnotetext{
${ }^{22}$ Although the economy only approaches the new steady-state asymptotically, we find that 1,000 time periods is sufficient for welfare to converge.

${ }^{23}$ Although we assume that the capital requirement is changed once and for all at $t=0$, the solution method works if $\zeta$ is time varying and follows any deterministic path.
} 
equation (17) and solve numerically for $\phi_{t}$ (and then recover $w_{t}$ ). Then, given $\phi_{t}, w_{t}$, and $R_{t}^{d}$, we use equation (20) to compute $d_{t+1}$, and we move to the next $t$.

Consumption at $t+1$ can be computed using the resource constraint of the economy. The amount of resources available at the beginning of $t+1$ are given by the output produced by firms, $\bar{z} l_{t}$, plus the output produced by bank-financed firms, $A k_{t}^{\gamma}$, and is used for consumption $c_{t+1}$ and investments. Since investments can be expressed as $k_{t+1}-(1-\delta) k_{t}$, we have

$$
\begin{aligned}
c_{t+1} & =\bar{z} l_{t}+A k_{t}^{\gamma}-\left[k_{t+1}-(1-\delta) k_{t}\right] \\
& =\bar{z} \phi_{t} d_{t}+A k_{t}^{\gamma}-\delta k_{t}-\left(k_{t+1}-k_{t}\right),
\end{aligned}
$$

where the second line uses $l_{t}=\phi_{t} d_{t}$ from Proposition 1 and rearranges.

To compute $W^{\text {wrong }}(\zeta)$, we note that Proposition 6 implies

$$
\left(W^{\text {wrong }}\right)^{\prime}(\zeta)=W^{\prime}(\zeta)+\sum_{t=0}^{\infty} \beta^{t+1}\left(\bar{z}-w_{t}\right)\left(\left.\frac{\partial l_{t}(\zeta)}{\partial \zeta}\right|_{w_{t} \text { fixed }}-\frac{\partial l_{t}(\zeta)}{\partial \zeta}\right)
$$

where we have emphasized the dependence of $l_{t}(\zeta)$ on $\zeta$. Fixing a value of $\zeta$, we set a small $\Delta>0$ and we use the approximations

$$
\frac{\partial W(\zeta)}{\partial \zeta} \approx \frac{W(\zeta+\Delta)-W(\zeta)}{\Delta}
$$

and

$$
\begin{aligned}
\left.\frac{\partial l_{t}(\zeta)}{\partial \zeta}\right|_{w_{t} \text { fixed }}-\frac{\partial l_{t}(\zeta)}{\partial \zeta} & \approx \frac{l_{t}^{\text {wrong }}(\zeta+\Delta)-l_{t}(\zeta)}{\Delta}-\frac{l_{t}^{\text {right }}(\zeta+\Delta)-l_{t}(\zeta)}{\Delta} \\
& =\frac{l_{t}^{\text {wrong }}(\zeta+\Delta)-l_{t}^{\text {right }}(\zeta+\Delta)}{\Delta} .
\end{aligned}
$$

The term $l_{t}^{\text {wrong }}(\zeta+\Delta)$ denotes the value of labor that arises by increasing the capital requirement to $\zeta+\Delta$ while keeping the wage $w_{t}$ fixed. The term $l_{t}^{\text {right }}(\zeta+\Delta)$ denotes the value of labor that arises by increasing the capital requirement to $\zeta+\Delta$ and allowing the wage $w_{t}$ to adjust. For each $t$, both values are computed by fixing the state variables used to compute $l_{t}(\zeta)$ but using the policy functions to compute the time- $t$ endogenous variables for $\zeta+\Delta$, and either fixing $w_{t}$ or allowing it to change depending on whether we compute $l_{t}^{\text {wrong }}(\zeta+\Delta)$ or $l_{t}^{\text {right }}(\zeta+\Delta)$, respectively.

In particular, we compute the time path of $d_{t}$ and $a_{t}$ for a given capital requirement change $\zeta$. Then at at each $t$, we compute the values $\hat{R}_{t}^{d}$ and $\hat{\phi}_{t}$ that would have obtained in that state, had the capital requirement in that state instead been $\zeta+\Delta$. Then $l_{t}^{\text {right }}(\zeta+\Delta)=\hat{\phi}_{t} d_{t}$. 
To compute $l_{t}^{\text {wrong }}(\zeta+\Delta)$, we find the value $\widetilde{\phi}_{t}$ that would obtain if the capital requirement were $\zeta+\Delta$, but the wage were as if the capital requirement were still $\zeta$. To do so, we note that since $z_{t+1}^{i}$ can only take the two values of 0 and $1 / p_{z}$, equation (17) can be solved for $\phi_{t}$ in closed form:

$$
\phi_{t}=R_{t}^{d} \frac{1-w_{t}}{w_{t}\left(\frac{1}{p_{z}}-w_{t}\right)}
$$

so that to compute $\widetilde{\phi}_{t}$, we replace $R_{t}^{d}$ in equation (47) with $\hat{R}_{t}^{d}$.

\section{C.3 Quantitative model}

The first-order conditions for $l_{t}$ and $n_{t}$ for problem (32), after plugging in the budget constraint, are

$$
\begin{aligned}
w_{t} & =\frac{\chi\left(l_{t}\right)^{\frac{1}{\eta}}}{E_{t}\left\{c_{t+1}^{-\gamma_{c}}\right\}} \\
1 & =E_{t}\left\{\beta\left(\frac{c_{t+1}}{c_{t}}\right)^{-\gamma_{c}} R_{t+1}^{n}\right\}
\end{aligned}
$$

Equation (48) would be a standard labor supply curve if it were not for the expecation on the right-hand side. This expectation appears in (48) because wages are earned at $t+1$ but labor is chosen at $t$. The expected-return condition for bank equity (49) is standard.

The banker's problem (30), after plugging in equation (31) and the constraints and rearranging, becomes

$$
\max _{p_{t}} E_{t} \int\left\{\varepsilon\left(1-\delta+r_{t+1}\right)-\left(1-p_{t}\right) R_{t}^{d}(1-\zeta)-\frac{\lambda p_{t}}{\left(1-p_{t}\right)^{\nu}}(1-\zeta)\right\}^{+} d F(\varepsilon)
$$

for which the first-order condition is equation (33), which we solve numerically for $p_{t}$. Notice also that the default threshold $\underline{\varepsilon}_{t+1}$ becomes

$$
\underline{\varepsilon}_{t+1}=\left(1-p_{t}\right)(1-\zeta) \frac{R_{t}^{d}-\lambda\left(p_{t}\right)}{1-\delta+r_{t+1}}
$$

The left-hand-side of equation (33) is the marginal benefit of benefit of increasing $p_{t}$, while the right-hand side is the marginal cost. The marginal cost is $\lambda$ at $p_{t}=\xi_{t}=0$ and rises to infinity as $p_{t} \rightarrow 1$, so if $R_{t}^{d}>\lambda, \xi_{t}=0$ and there is a single solution to equation (33) for $p_{t}$; otherwise $\xi_{t}=\lambda-R_{t}^{d}$ and the optimal $p_{t}=0$. 
In this economy there is a single exogenous state variable, $A_{t}$, and two endogenous state variables, which we denote $Y_{t}$ and $X_{t}$. The variable $Y_{t}$ is total output available for consumption and future investment. The variable $X_{t}$ is total wealth held by firms before they make dividend payments. That is,

$$
\begin{aligned}
Y_{t} & \equiv \phi_{t-1} d_{t-1}+A_{t} k_{t-1}^{\gamma}+(1-\delta) k_{t-1}-\lambda \frac{p_{t-1}}{\left(1-p_{t-1}\right)^{1+\nu}} d_{t-1} \\
X_{t} & \equiv\left[\left(\bar{z}-w_{t-1}\right) \phi_{t-1}+R_{t-1}^{d}\right] d_{t-1} .
\end{aligned}
$$

Notice that $X_{t}$ is pre-determined at $t-1$, much like $d_{t}$ was pre-determined at $t-1$ in the model of Section 3. However, in this model $\alpha_{t}$ is a choice variable of firms, so that $d_{t}$ satisfies:

$$
d_{t}=\left(1-\alpha_{t}\right) X_{t}
$$

where the dependence of $d_{t}$ on the state at $t$ comes from its dependence on $\alpha_{t}$.

We solve the model globally on a grid of values for the state variables. Instead of using $Y_{t}$ and $X_{t}$, however, we define

$$
\omega_{t} \equiv \log X_{t}-\psi_{0}-\psi_{1} \log Y_{t}
$$

where $\psi_{0}$ and $\psi_{1}$ are constants, and we solve the model over $\log Y_{t}$ and $\omega_{t}$. Solving the model on a grid for $\omega_{t}$ rather than $\log X_{t}$ is more accurate because $\log Y_{t}$ and $\log X_{t}$ are highly correlated in equilibrium, so that solving on a grid of $\log Y$ and $\log X$ would include node points that occur with extremely low probabilities in the ergodic distribution.

We choose five points for $\log A_{t}$ using the method of Rouwenhorst (1995), and for each $\log A_{t}$ point we approximate $\alpha_{t}, R_{t}^{d}, w_{t}$, and $\phi_{t}$ as fifth-order Chebyshev polynomials on a grid of 36 points for $\log Y_{t}$ and $\omega_{t}$. In particular, at each of the $5 \times 36=180$ node points, we solve equations (48) and (17) for $w_{t}$ and $\phi_{t}$, given $d_{t}$ and $R_{t}^{d}$, and equations (49) and (29) for $R_{t}^{d}$ and $\alpha_{t}$, given $p_{t}, \phi_{t}$, and $w_{t}$. We then solve equation (33) for the optimal $p_{t}$, setting $p_{t}=0$ if $R_{t}^{d}(1-\zeta)<\lambda$. We solve equations (49) and (29) using the household's budget constraint

$$
\begin{aligned}
c_{t} & =Y_{t}-k_{t} \\
& =Y_{t}-\frac{1-\alpha_{t}}{1-\zeta_{t}} X_{t},
\end{aligned}
$$


and iterating it forward for $c_{t+1}$ using the law of motion for the endogenous states:

$$
\begin{aligned}
Y_{t+1} & =\phi_{t} d_{t}+A_{t+1} k_{t}^{\gamma}+(1-\delta) k_{t}-\lambda \frac{p_{t}}{\left(1-p_{t}\right)^{1+\nu}} d_{t} \\
X_{t+1} & \equiv\left[\left(\bar{z}-w_{t}\right) \phi_{t}+R_{t}^{d}\right]\left(1-\alpha_{t}\right) X_{t}
\end{aligned}
$$

This procedure requires a guess for $\left(\phi_{t}, w_{t}, p_{t}\right)$ to solve for $\left(\alpha_{t}, R_{t}^{d}\right)$, and a guess for $\left(\alpha_{t}, R_{t}^{d}\right)$, to solve for $\left(\phi_{t}, w_{t}\right)$, at each node-point. Given $R_{t}^{d}$, we solve for $\left(w_{t}, \phi_{t}\right)$ by searching over values of $w_{t}$ to satisfy equation (21) after plugging in equation (47).

We solve equations (29) and (49) for $\left(\alpha_{t}, R_{t}^{d}\right)$, given $\left(w_{t}, \phi_{t}\right)$ and using a guess for the interpolated $\alpha$ function (i.e., evaluated at any state) that allows us to compute expectations of $c_{t+1}$ at time $t$ for each node point. We start with a guess for each variable from the quasi-linear utility model, and iterate until the maximum percent change across the five endogenous variables from iteration to iteration is zero to 3 decimal places in absolute value.

After solving for $\left(\alpha_{t}, R_{t}^{d}\right)$, we update the value of $p_{t}$ by inverting equation (33) to get $p_{t}=p\left(R_{t}^{d}\right)$, which we linearly interpolate on a grid of 1,000 points for $R_{t}^{d}$ from $\lambda$ to 1.06. $p_{t}=0$ whenever $R_{t}^{d}<\lambda$. This "kink" at $R_{t}^{d}=\lambda$ is why we do not interpolate $p_{t}$ using Chebyshev polynomials at the node-points, as for the other endogenous state variables; instead we set $p_{t}=p\left(R_{t}^{d}\right)$ dynamically during simulations, since this function depends only on parameters and $R_{t}^{d}$.

After solving the model equations, we simulate 1,000 economies for 700 periods each in order to verify that the model remains within the assumed bounds for the endogenous state variables. Each simulation starts at the steady-state of the quasi-linear utility model.

To estimate the implied moments of the model, we compute averages over time and over the 1,000 simulated economies, throwing away the first 200 observations of each simularion to reduce dependence on the initial state.

To compute welfare for a change to $\zeta$, we again simulate 1,000 economies, but this time for 900 periods, throwing away the first 200 periods to reduce dependence on the initial state, and assuming $\zeta$ jumps immediately to a new value at $t=400$. This implies no change to either state variable, but does change the endogenous policy functions $\alpha, \phi, w$, and $R^{d}$ as a function of the state. We compute the 1,000 simulations for 150 values of $\zeta$ between 0.07 and 0.3 , and find maximum and minimum values of $\log Y$ and $\omega$ that are common to all 150 values of $\zeta$ (plus the initial $\zeta_{0}$ economy). We then solve the model for each value of $\zeta$ on this common, enlarged grid; we use the same values of $\psi_{0}$ and $\psi_{1}$ in each economy. Were we to allow a different Chebyshev grid for the endogenous state variables for each value of $\zeta$, changes in the grid would result in spurious differences to the computed welfare and would be evident in Figure 5 as jagged discontinuities. 
For the model parameters reported in Table 1 , we use $\psi_{0}=-1.05$ and $\psi_{1}=1.4$. For these values of $\psi_{0}$ and $\psi_{1}$, we find that for values of $\zeta$ ranging from $7 \%$ to $30 \%$ we can solve the model on a grid of $(0.8,1.2)$ for $\log Y$ and $(-0.29,0.13)$ for $\omega$.

To compute $W^{\text {wrong }}(\zeta)$ in the quantitative model, we follow the same procedure described in Appendix C.2, with some adjustments. First, we replace the $\bar{z}-w_{t}$ terms in equation (45) with $u^{\prime}\left(c_{t+1}\right)\left(\bar{z}-w_{t}\right)$ to account for the more general utility function. ${ }^{24}$ Second, we average over simulations rather than computing a single deterministic path. In other words, we have that

$$
\begin{aligned}
\frac{\partial W^{\text {wrong }}(\zeta)}{\partial \zeta} & =\frac{\partial W(\zeta)}{\partial \zeta} \\
& +E\left\{\sum_{t=0}^{\infty} \beta^{t+1} u^{\prime}\left(c_{t+1}\right)\left(\bar{z}-w_{t}\right) \frac{l_{t}^{\text {wrong }}(\zeta+\Delta)-l_{t}^{\text {right }}(\zeta+\Delta)}{\Delta}\right\}
\end{aligned}
$$

We approximate the expectation in equation (50) using the same simulations that we use to compute "correct" welfare; the key difficulty is in approximating $l_{t}^{\text {right }}(\zeta+\Delta)$ and $l_{t}^{\text {wrong }}(\zeta+\Delta)$ for all $t$ and $\zeta$. To do so, for each value of $t$ (and for any given $\zeta$ ) we use the simulated state $\left(A_{t}, Y_{t}, X_{t}\right)$ and evaluate the optimal $\alpha_{t}$ and $\phi_{t}$ at this state, but using the policy functions for $\alpha$ and $\phi$ computed not for $\zeta$, but for $\zeta+\Delta$. Then $l_{t}^{\text {right }}(\zeta+\Delta)=$ $\phi_{t}\left(1-\alpha_{t}\right) X_{t}$ is straightforward. Notice that these estimated functions implicitly use the correct wage for $\zeta+\Delta$, i.e. they do allow the wage to adjust as $\zeta$ changes.

To compute $l_{t}^{\text {wrong }}(\zeta+\Delta)$, we compute $\alpha_{t}$ and $R_{t}^{d}$ using the $\zeta+\Delta$ functions, evaluated at the state at $t$. Then instead of using the $\phi_{t}$ function as we did for $l_{t}^{\text {right }}(\zeta+\Delta)$, we compute a new $\phi$ using equation (47) and the actual $w_{t}$ (i.e., the wage that obtains when $\zeta$ does not change).

\footnotetext{
${ }^{24}$ This result can be derived similar to the proof of Proposition 6, using the first-order condition for households' labor supply of the quantitative model (i.e., equation 48) rather than that of the baseline model (i.e., equation 21).
} 